\title{
Prediction of Shear Lag Effect in Thin-Walled Single-Box Multicell Box Girder Based on the Modified Warping Displacement Function
}

\author{
Xiayuan Li, ${ }^{1}$ Shui Wan $\mathbb{D}^{1},{ }^{1}$ Kongjian Shen, ${ }^{2}$ Peng Zhou, ${ }^{1}$ and Xiao Wang ${ }^{1}$ \\ ${ }^{1}$ School of Transportation, Southeast University, Nanjing 210096, China \\ ${ }^{2}$ Jiangsu Provincial Transportation Engineering Construction Bureau, Nanjing 210004, China \\ Correspondence should be addressed to Shui Wan; lanyu421@163.com
}

Received 14 January 2020; Accepted 24 April 2020; Published 15 May 2020

Academic Editor: Emanuele Brunesi

Copyright (c) 2020 Xiayuan Li et al. This is an open access article distributed under the Creative Commons Attribution License, which permits unrestricted use, distribution, and reproduction in any medium, provided the original work is properly cited.

\begin{abstract}
In this study, an effective and accurate theoretical analysis method for predicting the shear lag effect in the thin-walled single-box multicell box girder is presented. The modifications of longitudinal warping displacement functions at the flanges are fully investigated, including the shear lag width $\left(b_{i j}\right)$ of flanges, the coefficients $\left(\alpha_{i j}\right)$ of shear lag warping functions, the deformation compatibility conditions in flanges, and the internal force balance $(D)$. The initial shear deformation $\left(\gamma_{03}\right)$ in the top lateral cantilever flanges is innovatively introduced in multicell box girders and obtained by the designed procedure. In addition, the transverse distribution function for describing the longitudinal warping displacement is deduced and expressed in the form of the cosine function. Based on the principle of minimum potential energy, the governing differential equations are derived and solved with the associated boundary and load conditions. The accuracy and applicability of the proposed method (SL-THY2) are validated for four thin-walled single-box multicell (two- and three-cell) box girders with the results derived from the solid finite element method.
\end{abstract}

\section{Introduction}

The shear lag (SL) effect, describing the nonuniform normal stress distribution in the flanges of thin-walled flexural members, has been the subject of many papers and experimental works for decades since first examined by aeronautical engineers $[1,2]$ and later widely studied for thinwalled single-cell box girder bridges in engineering design practice. The research on the shear lag effect mainly involves two aspects-shear lag coefficient distribution and vertical deflections of the girder, for the structural behaviors can be different from those predicted by elementary beam theory [3-7].

In the past decades, extensive theoretical and experimental studies have been performed on the phenomenon of shear lag in thin-walled single-cell box girders in order to develop a reliable method, and considerable progress has been achieved, especially for Reissner [1], Dezi and Mentrasti [2], Luo [8-11], Zhang [12-15], and Lin [16, 17], who promoted the development of theoretical analysis on the shear lag effect by using the energy variation method. To improve the precision, accuracy, and perfect the theory research for predicting the shear lag effect in a thin-walled single-cell box girder, much work has been conducted and can be further summarized as follows: (1) the selection of an appropriate transverse distribution function for describing the warping displacement in flanges, assuming to be quadratic parabolic $[1,2,12-15,18,19]$, cubic parabolic [8-10], cosine $[3-5,20]$, and polynomial $[16,17]$; (2) the independent functions are employed for describing the warping displacement in the flanges [2, 8-10]; (3) the introduction of coefficients of shear lag warping functions at the flanges $[3,4,15]$; (4) the consideration of internal force balance in building warping displacement functions [3, 4, 12-15]; 
(5) the influence of shear deformation in webs on the bending curvature $[3,4]$, and so on. However, according to the companion papers $[3,9,12-15]$, when the width of the top lateral cantilever flange is half of the top central flange, the normal stress at the web-flange junction can be well predicted, while for those far from the web-flange junction, the error cannot be neglected. The main reason can be explained by lacking theoretical foundation and rationality verification in selecting the transverse distribution function for longitudinal warping displacement and by ignoring the difference of boundary condition between the top lateral cantilever flanges and the flanges in the closed section. $\mathrm{Li}$ et al. [3] proposed the initial shear rotation for describing the additional warping displacement in top lateral cantilever flanges for the thin-walled single-cell box girder and designed a practical procedure to calculate it.

Nevertheless, the studies included in the aforementioned literature reviews are mainly focused on analyzing the shear lag effect in a thin-walled single-cell box girder, and the investigations on the shear lag effect in the multicell box girder, to the authors' best knowledge, are limited. More importantly, with the rapid increase of traffic flow, the wide multicell box girders are rapidly applied in highway and municipal bridges in recent years, especially in China, to provide more traffic lanes. As a result, it is desirable to develop a reasonable and reliable theoretical method for predicting the shear lag effect in thin-walled single-box multicell box girders.

The objective of this study is to develop an effective and accurate theoretical analysis method for predicting the shear lag effect in thin-walled single-box multicell box girders. To this end, the longitudinal warping displacement functions for the flanges are fully investigated. According to the bending shear flow distribution, the widths of flanges are redivided and defined as shear lag width $\left(b_{i j}\right)$, and the coefficients of shear lag warping function $\left(\alpha_{i j}\right)$ are determined as well. In addition, the deformation compatibility conditions in flanges are considered, and the correction factors $\left(\xi_{k}\right)$ are introduced and solved by the given equations. The initial shear deformation $\left(\gamma_{03}\right)$ in the top lateral cantilever flanges is innovatively introduced in the multicell box girder and obtained by the designed procedure. The governing differential equations, based on the principle of minimum potential energy, are derived and solved with the associated boundary and load conditions. In addition, the finite element analysis is proved to be feasible through the sensitivity analysis of mesh size, and the accuracy and applicability of the proposed method (SL-THY2) are validated with the results of solid finite element analyses conducted on four different multicell (two- and three-cell) box girders.

\section{Modified Longitudinal Warping Displacement Functions}

The aim is to study the shear lag effect in thin-walled singlebox multicell box girders, as illustrated in Figure 1, where the loads are applied parallel to the middle plane of the webs uniformly in order to avoid torsion, distortion, and transverse bending of the cross section [2]. The components of the single-box multicell box girder are composed of basic elements: top and bottom central flanges (or central flanges instead), top lateral cantilever flanges, and webs. The $x$-axis is taken to coincide with the centroid axis along the beam span direction, and $y$ - and $z$-axes are taken as the principal inertial directions. In addition, for the simplicity of building longitudinal warping displacement functions in flanges, the local coordinates are also introduced, as shown in Figure 1.

2.1. Basic Assumptions. The shear lag phenomenon can be analyzed on the basis of the theory of elasticity by assuming the flanges and webs can be analyzed as a plane-stress problem [21], and the basic assumptions can be summarized as follows:

(1) The normal strain and in-plane shear strain are uniformly distributed along wall-thickness direction

(2) The out-plane shear deformation and transverse deformation in flanges are negligible

(3) Due to the assumption of thin-walled beam theory, the primary shear force is assumed to be entirely carried by the webs

(4) The flanges and webs behave in a linear-elastic fashion

(5) The deformations are quite small compared with the dimensions of the cross section

Based on the above assumptions and the generation mechanism of shear lag phenomenon [22, 23], the longitudinal warping displacement functions in the flanges, including the constant contribution from bending according to Timoshenko beam theory (TBT) and the shear lag contribution, can be rationally written as $[3,4]$

$$
u_{i j}=u_{\mathrm{SL}, i j}(x, y)+u_{\phi, r}(x, z) \text {, }
$$

in which, $u_{\mathrm{SL}, i j}(x, y)(i=1, \ldots .2, j=1, \ldots, \zeta$, and $i=3)$ is the shear lag warping displacement contribution; the exponent $i$ (from 1 to 3 ) in the functions represents the bottom central flanges, top central flanges, and the top lateral cantilever flanges, respectively; the exponent $j$ (from 1 to $\zeta$, where $\zeta$ is the number of cells) in the functions represents the partition of flanges, as shown in Figure $1 ; u_{\phi, r}(x, z)(r=1, \ldots, 3)$ is the bending warping displacement contribution, considering shear deformation in webs.

According to the companion paper [1], the longitudinal warping displacement that remotes from the web-flange junction lags behind that at the web-flange junction, and thus, the expressions of shear lag warping displacement functions of flanges can be given in the form

$$
u_{\mathrm{SL}, i j}(x, y)=\psi_{i j}(y) U_{i j}(x)
$$

where $\psi_{i j}(y)(i=1, \ldots, 2, j=1, \ldots, \zeta$, and $i=3)$ is the transverse distribution function of the longitudinal warping displacement of the flange and $U_{i j}(x)(i=1, \ldots, 2, j=1, \ldots$, $\zeta$, and $i=3)$ is the shear lag warping function of the corresponding flanges. 


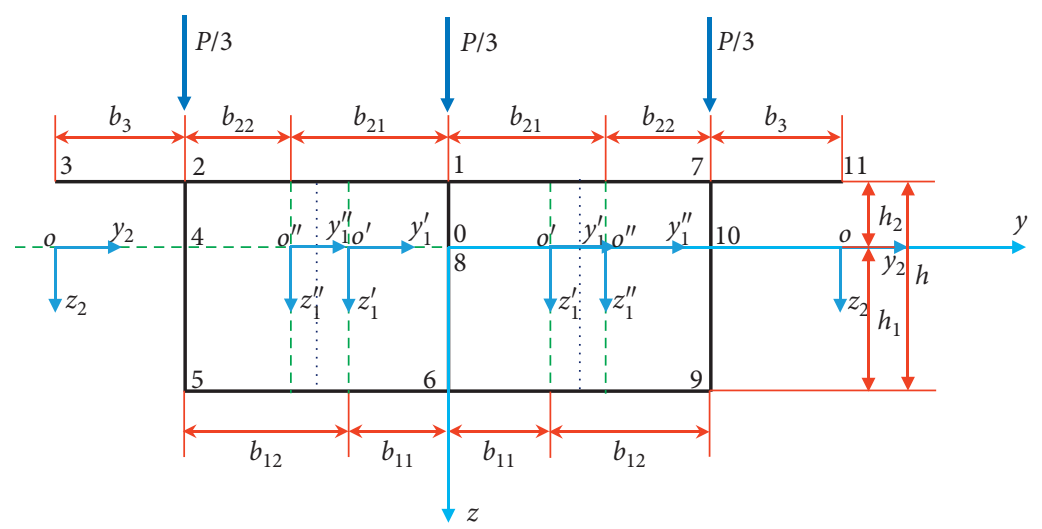

(a)

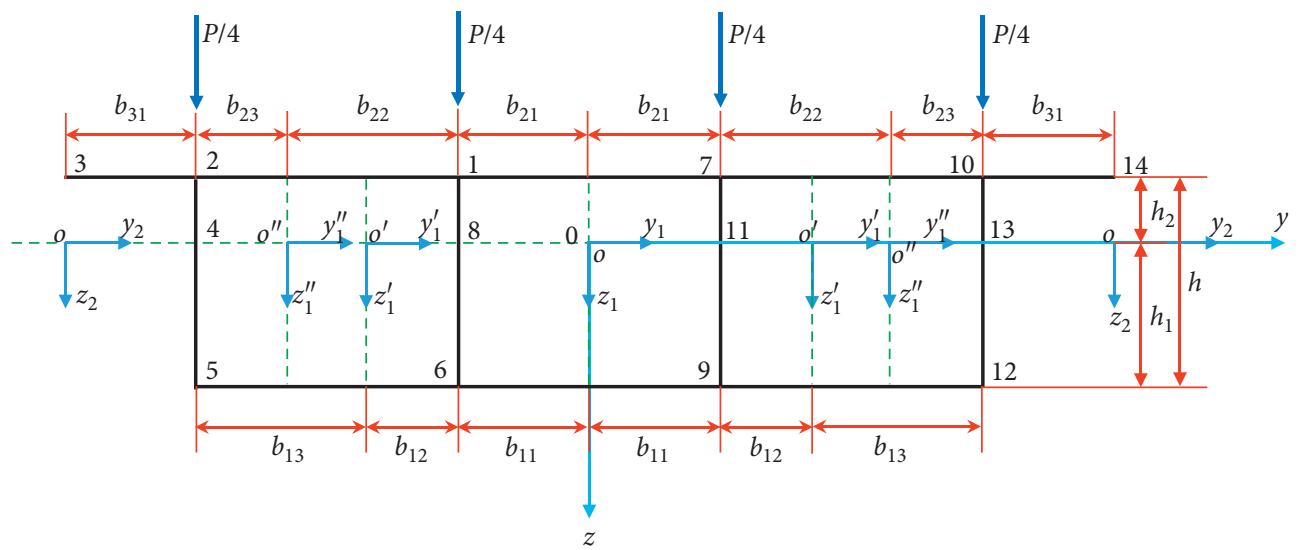

(b)

FIgURE 1: Cross section of the multicell box girder: (a) single-box two-cell (1B2C) $(\zeta=2)$; (b) single-box three-cell $(1 \mathrm{~B} 3 \mathrm{C})(\zeta=3)$.

In addition, according to the definition of equation (2), the boundary conditions of the transverse distribution function $\psi_{i j}(y)$ at the flanges should satisfy

$$
\begin{gathered}
\left.\psi_{i j}(y)\right|_{y=b_{i j}}=0, \\
\left.\psi_{i j}(y)\right|_{y=0}=1 .
\end{gathered}
$$

The constant contribution of bending according to TBT, considering the shear deformation in webs, is given by [3]

$$
\begin{aligned}
& u_{\phi, r}(x, z)=-\phi(x) h_{m}, \\
& \phi(x)=w^{\prime}(x)-\beta(x),
\end{aligned}
$$

in which, $\phi(x)$ is the angle of rotation of the cross section; $h_{m}(m=1,2$, where $m=1$ denotes the bottom flanges and $m=2$ denotes the top flanges) is the distance between the midsurface of the flanges and the neutral axis, which must be given to the sign; $w^{\prime}(x)$ is the first derivative of the deflection of the girder with respect to $x ; \beta(x)=\alpha\left(Q(x) / G A_{w}\right)$ is the average of the shear strain; $\alpha$ is the shear factor; $Q(x)$ is the shearing force; $G$ is the shear modulus; $A_{w}=(\zeta+1) t_{w} h_{w}$ is the total area of the webs; $h_{w}$ is the web depth; and $t_{w}$ is the web thickness.
2.2. Bending Shear Flow Distribution. The shear lag phenomenon is mainly caused by the lag of shear strains in the flanges between the webs [24]; hence, the study of bending shear flow distribution for multicell cross section is quite necessary.

For the case of the multicell cross section of the box girder, the bending shear flow, $q_{j}(s)$, can be given by [24]

$$
q_{j}(s)=\underbrace{p_{j}}_{\text {constant }}+\underbrace{p_{b, j}(s)}_{\text {variable }},
$$

where $p_{j}(j=1, \ldots, \zeta$, where $\zeta$ is the number of cells) represents the indeterminate shear flow, which is constant across the $j^{\text {th }}$ cell; $p_{b, j}(s)=-Q(x) S_{y} / I_{y}$ represents the variable shear flow due to the bending, and the slit is inserted at points 1,7 , and 10 of the closed cross section, as illustrated in Figure 1; $S_{y}$ represents the static moments with respect to $y$; and $I_{y}$ represents the moment of inertia of the cross section with respect to $y$.

Since the slit inserted at points 1, 7, and 10 of the closed cross section is a hypothetical existence, the condition of deformation compatibility should be satisfied, based on which the indeterminate shear flow $p_{j}$ can be solved by the following equations [24]: 


$$
\begin{array}{r}
\oint_{1} \frac{q_{1}(s)}{G t_{1}} \mathrm{~d} s-\int_{1,2} \frac{q_{2}(s)}{G t_{w}} \mathrm{~d} s=0, \\
\oint_{j} \frac{q_{j}(s)}{G t_{j}} \mathrm{~d} s-\int_{j, j-1} \frac{q_{j-1}(s)}{G t_{w}} \mathrm{~d} s-\int_{j, j+1} \frac{q_{j+1}(s)}{G t_{w}} \mathrm{~d} s=0, \\
\oint_{\xi} \frac{q_{\xi}(s)}{G t_{\xi}} \mathrm{d} s-\int_{\xi, \xi-1} \frac{q_{\xi-1}(s)}{G t_{w}} \mathrm{~d} s=0,
\end{array}
$$

where $\oint_{j} q_{j}(s) / G t_{j} \mathrm{~d} s$ is the contour closed integral for the $j^{\text {th }}$ cell, $\int_{j, j-1}\left(q_{j-1}(s) / G t_{w}\right) \mathrm{d} s$ is the integral for boundary webs between $j^{\text {th }}$ and $(j-1)^{\text {th }}$ cells, and $\int_{j, j+1}\left(q_{j+1}(s) / G t_{w}\right) \mathrm{d} s$ is the integral for boundary webs between $j^{\text {th }}$ and $(j+1)^{\text {th }}$ cells.

According to equation (6), once $p_{j}(j=1, \ldots, \zeta)$ is determined, the shear flow distribution throughout the multicell cross section can be plotted easily in Figure 2, and the directions of shear flow are indicated by the arrows.

As can be seen from Figure 2, the shear flow converges and diverges at the positions of the web-flange junction and of zero points of bending shear flow. It should be noted that the positions of zero points of bending shear flow are not located at half flange-width, instead, beyond a certain distance. Hence, the width of the flanges needs to be reconsidered based on the positions of zero points of the bending shear flow.

2.2.1. Shear Lag Width of Flanges $b_{i j}$. Since the shear flow distribution, $q_{j}(s)$, is determined by the preceding procedure, it is convenient to define the term shear lag width of flanges $\left(b_{i j}\right.$, where $\left.i=1, \ldots, 2, j=1, \ldots, \zeta\right)$, which refers to the width between the positions of zero points of the bending shear flow and webs, as shown in Figure 2. The positions of zero points of the bending shear flow can be obtained by solving

$$
q_{j}(s)=p_{j}+p_{b, j}(s)=0 .
$$

As a result, the shear lag width of flanges $\left(b_{i j}\right)$ in the thinwalled single-box multicell box section can be obtained, as plotted in Figure 1.

In addition, the geometric equation that the relationship between displacements $u_{i j}$ and $v$ in the direction of coordinate axes $(x, y)$ can be written as [24]

$$
\gamma_{x y}=\frac{\partial u_{i j}}{\partial y}+\frac{\partial v}{\partial x}
$$

where $v$ is the transverse deformation, and $v=0$ (according to assumption 2).

At those positions of the shear flow which is equal to zero, the substitution of equations (2) and (4) into equation (9) gives the boundary condition of the transverse distribution function with respect to $y$, that is,

$$
\left.\frac{\partial \psi_{i j}(y)}{\partial y}\right|_{y=0}=0
$$

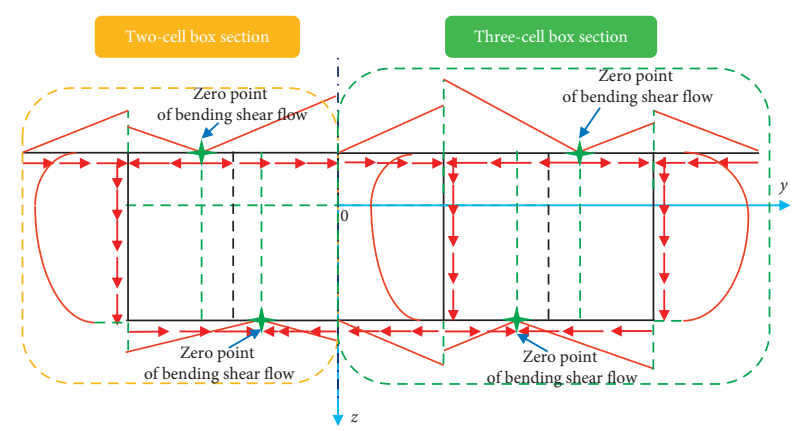

FIgURE 2: Bending shear flow in the single-box multicell box girder.

2.2.2. Coefficients of Shear Lag Warping Functions $\alpha_{i j}$. Within the shear lag width of flanges $\left(b_{i j}\right)$, the maximum value of the longitudinal warping displacement, $\Delta u_{i j}$, varies and can be expressed by integrating equation (9) with respect to $y$ :

$$
\Delta u_{i j}=\int_{0}^{b_{i j}} \gamma_{x y} \mathrm{~d} y=-\frac{\mathrm{Q}(x)}{2 G I_{y}} h_{m} b_{i j}^{2},
$$

where $b_{i j}(i=1, \ldots, 2, j=1, \ldots, \zeta$, and $i=3)$ represents the shear lag width of the flanges, as shown in Figure 1.

Since the shearing force, $Q(x)$, is unknown, it is not convenient to determine the maximum value for the longitudinal warping displacement. However, the relationship of the maximum value for the longitudinal warping displacement between different shear lag widths of flanges can be determined and expressed in the form of the coefficient $\alpha_{i j}$ :

$$
\alpha_{i j}=\frac{\Delta u_{i j}}{\Delta u_{21}}=-\frac{b_{i j}^{2} h_{m}}{b_{21}^{2} h_{2}} .
$$

From this general equation, the coefficient $\left(\alpha_{i j}\right)$ subjected to various loads can be determined and only with regard to geometric parameters.

Furthermore, the maximum value for the longitudinal warping displacement, $\Delta u_{i j}$, can also be expressed by substituting the boundary condition of transverse distribution function equations (3a) and (3b) into equation (2), which yields

$$
\Delta u_{i j}=U_{i j}(x)
$$

Accordingly, equation (12) can be given in the form

$$
\alpha_{i j}=\frac{U_{i j}(x)}{U_{21}(x)}=-\frac{b_{i j}^{2} h_{m}}{b_{21}^{2} h_{2}} .
$$

Finally,

$$
U_{i j}(x)=\alpha_{i j} U_{21}(x) .
$$

Given that $U_{21}(x)=-\alpha_{21} U(x)$ (where $\alpha_{21}$ is equal to 1 , from equation (14)), equation (15) can be written as

$$
U_{i j}(x)=-\alpha_{i j} U(x) .
$$


The term $\alpha_{i j}$ is defined as the coefficients of shear lag warping functions for the corresponding flanges; $U(x)$ is the normalized shear lag warping function.

2.3. Continuity of Shear Lag Warping Displacement Function. The shear lag warping displacement function $u_{\mathrm{SL}, i j}(x, y)$ can be rewritten from equations (2) and (16) as

$$
u_{\mathrm{SL}, i j}(x, y)=-\alpha_{i j} U(x) \psi_{i j}(y) .
$$

These shear lag warping displacement functions should definitely satisfy the continuity conditions at the positions of zero points of bending shear flow and the positions of webflange junctions.

For the case of $1 \mathrm{~B} 2 \mathrm{C}$, at the positions of zero points of bending shear flow $(y=0)$ in the top central flanges, the shear lag warping displacements $u_{\mathrm{SL}, 21}$ and $u_{\mathrm{SL}, 22}$ are as follows:

$$
\begin{aligned}
& u_{\mathrm{SL}, 21}(x, y=0)=-\alpha_{21} U(x), \\
& u_{\mathrm{SL}, 22}(x, y=0)=-\alpha_{22} U(x) .
\end{aligned}
$$

Since $b_{21} \neq b_{22}$, then $\alpha_{21} \neq \alpha_{22}$ (according to equation (12)), which yields

$$
u_{\mathrm{SL}, 21}(x, y=0) \neq u_{\mathrm{SL}, 22}(x, y=0) .
$$

Similarly,

$$
u_{\mathrm{SL}, 11}(x, y=0) \neq u_{\mathrm{SL}, 12}(x, y=0) .
$$

For the case of $1 \mathrm{~B} 3 \mathrm{C}$, the same conclusions can also be obtained as follows:

$$
\begin{aligned}
& u_{\mathrm{SL}, 22}(x, y=0) \neq u_{\mathrm{SL}, 23}(x, y=0), \\
& u_{\mathrm{SL}, 12}(x, y=0) \neq u_{\mathrm{SL}, 13}(x, y=0) .
\end{aligned}
$$

As a result, equation (17) does not satisfy the continuity condition at the positions of zero points of the bending shear flow and needs to be further reorganized as follows.

For the case of 1B2C, the shear lag warping displacement function $u_{\mathrm{SL}, i j}^{1}(x, y)$ is given by

$$
u_{\mathrm{SL}, i j}^{1}(x, y)= \begin{cases}\left(-\alpha_{21} \psi_{i j}(y)+\alpha_{21}-\alpha_{22}\right) U(x), & 0 \leq y \leq b_{21}, \\ -\alpha_{22} \psi_{i j}(y) U(x), & 0 \leq y \leq b_{22}, \\ -\alpha_{3} \psi_{i j}(y) U(x), & 0 \leq y \leq b_{3}, \\ \left(\alpha_{11} \psi_{i j}(y)-\alpha_{11}-\alpha_{12}\right) U(x), & 0 \leq y \leq b_{11}, \\ \alpha_{12} \psi_{i j}(y) U(x), & 0 \leq y \leq b_{12},\end{cases}
$$

and the shear lag warping displacement function $u_{\mathrm{SL}, i j}^{2}(x, y)$ is given by

$$
u_{\mathrm{SL}, i j}^{2}(x, y)= \begin{cases}-\alpha_{21} \psi_{i j}(y) U(x), & 0 \leq y \leq b_{21}, \\ \left(-\alpha_{22} \psi_{i j}(y)+\alpha_{22}-\alpha_{21}\right) U(x), & 0 \leq y \leq b_{22}, \\ \left(-\alpha_{3} \psi_{i j}(y)+\alpha_{22}-\alpha_{21}\right) U(x), & 0 \leq y \leq b_{3}, \\ \alpha_{11} \psi_{i j}(y) U(x), & 0 \leq y \leq b_{11}, \\ \left(\alpha_{12} \psi_{i j}(y)-\alpha_{12}-\alpha_{11}\right) U(x), & 0 \leq y \leq b_{12} .\end{cases}
$$

Similarly, for the case of $1 \mathrm{~B} 3 \mathrm{C}$, the shear lag warping displacement function $u_{\mathrm{SL}, i j}^{1}(x, y)$ is given by

$$
u_{\mathrm{SL}, i j}^{1}(x, y)= \begin{cases}\left(-\alpha_{21} \psi_{i j}(y)+\alpha_{22}-\alpha_{23}\right) U(x), & 0 \leq y \leq b_{21}, \\ \left(-\alpha_{22} \psi_{i j}(y)+\alpha_{22}-\alpha_{23}\right) U(x), & 0 \leq y \leq b_{22}, \\ -\alpha_{3} \psi_{i j}(y) U(x), & 0 \leq y \leq b_{23}, \\ -\alpha_{3} \psi_{i j}(y) U(x), & 0 \leq y \leq b_{3}, \\ \left(\alpha_{11} \psi_{i j}(y)-\alpha_{12}+\alpha_{13}\right) U(x), & 0 \leq y \leq b_{11}, \\ \left(\alpha_{12} \psi_{i j}(y)-\alpha_{12}+\alpha_{13}\right) U(x), & 0 \leq y \leq b_{12}, \\ \alpha_{13} \psi_{i j}(y) U(x), & 0 \leq y \leq b_{13},\end{cases}
$$

and the shear lag warping displacement function $u_{\mathrm{SL}, i j}^{2}(x, y)$ is given by

$$
u_{S L, i j}^{2}(x, y)= \begin{cases}-\alpha_{21} \psi_{i j}(y) U(x), & 0 \leq y \leq b_{21}, \\ -\alpha_{22} \psi_{i j}(y) U(x), & 0 \leq y \leq b_{22}, \\ \left(-\alpha_{23} \psi_{i j}(y)+\alpha_{23}-\alpha_{22}\right) U(x), & 0 \leq y \leq b_{23}, \\ \left(-\alpha_{3} \psi_{i j}(y)+\alpha_{23}-\alpha_{22}\right) U(x), & 0 \leq y \leq b_{3}, \\ \alpha_{11} \psi_{i j}(y) U(x), & 0 \leq y \leq b_{11}, \\ \alpha_{12} \psi_{i j}(y) U(x), & 0 \leq y \leq b_{12}, \\ \left(\alpha_{13} \psi_{i j}(y)-\alpha_{13}-\alpha_{12}\right) U(x), & 0 \leq y \leq b_{13},\end{cases}
$$

where $u_{\mathrm{SL}, i j}^{1}(x, y)$ denotes the first method for modification of shear lag warping displacement function and $u_{\mathrm{SL}, i j}^{2}(x, y)$ denotes the second method for modification of shear lag warping displacement function.

It can be seen that the shear lag warping displacement functions $u_{\mathrm{SL}, i j}^{1}(x, y)$ and $u_{\mathrm{SL}, i j}^{2}(x, y)$ are linearly independent; hence, the expression of shear lag warping displacement function can be the combination of $u_{\mathrm{SL}, i j}^{1}(x, y)$ and $u_{\mathrm{SL}, i j}^{2}(x, y)$ and further be rewritten as follows.

For the top central and lateral cantilever flanges $(i=2$, $j=1, \ldots, \zeta$, and $i=3$ ),

$$
u_{\mathrm{SL}, i j}(x, y)=\frac{m_{1}}{m_{1}+m_{2}} \cdot u_{\mathrm{SL}, i j}^{1}(x, y)+\frac{m_{2}}{m_{1}+m_{2}} \cdot u_{\mathrm{SL}, i j}^{2}(x, y),
$$

$m_{1}+m_{2} \neq 0$. 
For bottom central flanges $(i=1, j=1, \ldots, \zeta)$,

$$
\begin{array}{r}
u_{\mathrm{SL}, i j}(x, y)=\frac{m_{3}}{m_{3}+m_{4}} \cdot u_{\mathrm{SL}, i j}^{1}(x, y)+\frac{m_{4}}{m_{3}+m_{4}} \cdot u_{\mathrm{SL}, i j}^{2}(x, y), \\
m_{3}+m_{4} \neq 0,
\end{array}
$$

where the coefficients $m_{1}, m_{2}, m_{3}$, and $m_{4}$ are the unknown constants.

Compared with equation (17), it should be noticed that the additional correction term introduced in equations (23a) and (23b) should not generate additional internal force in the top and bottom flanges.

Thus, for the case of $1 \mathrm{~B} 2 \mathrm{C}$, which should satisfy

$$
\begin{gathered}
\frac{m_{1}}{m_{1}+m_{2}}\left(\alpha_{21}-\alpha_{22}\right) E U^{\prime} A_{21}+\frac{m_{2}}{m_{1}+m_{2}} \\
\cdot\left(\alpha_{22}-\alpha_{21}\right) E U^{\prime}\left(A_{22}+A_{3}\right)=0, \\
\frac{m_{3}}{m_{3}+m_{4}}\left(-\alpha_{11}+\alpha_{12}\right) E U^{\prime} A_{11}+\frac{m_{4}}{m_{3}+m_{4}} \\
\cdot\left(-\alpha_{12}+\alpha_{11}\right) E U^{\prime} A_{12}=0 .
\end{gathered}
$$

Solving the above set of equations for $m_{1}, m_{2}, m_{3}$, and $m_{4}$ and substituting the values into $\left(m_{1} / m_{1}+m_{2}\right),\left(m_{2} /\right.$ $\left.m_{1}+m_{2}\right),\left(m_{3} / m_{3}+m_{4}\right)$, and $\left(m_{4} / m_{3}+m_{4}\right)$, we obtain

$$
\begin{aligned}
& \zeta_{1}=\frac{m_{1}}{m_{1}+m_{2}}=\frac{A_{22}+A_{3}}{A_{21}+A_{22}+A_{3}}, \\
& \zeta_{2}=\frac{m_{2}}{m_{1}+m_{2}}=\frac{A_{21}}{A_{21}+A_{22}+A_{3}}, \\
& \zeta_{3}=\frac{m_{3}}{m_{3}+m_{4}}=\frac{A_{12}}{A_{11}+A_{12}}, \\
& \zeta_{4}=\frac{m_{4}}{m_{3}+m_{4}}=\frac{A_{11}}{A_{11}+A_{12}} .
\end{aligned}
$$

Similarly, for the case of $1 \mathrm{~B} 3 \mathrm{C}$, which should satisfy

$$
\begin{aligned}
& \frac{m_{1}}{m_{1}+m_{2}}\left(\alpha_{22}-\alpha_{23}\right) E U^{\prime}\left(A_{21}+A_{22}\right)+\frac{m_{2}}{m_{1}+m_{2}} \\
& \cdot\left(\alpha_{23}-\alpha_{22}\right) E U^{\prime}\left(A_{23}+A_{3}\right)=0, \\
& \frac{m_{3}}{m_{3}+m_{4}}\left(-\alpha_{12}+\alpha_{13}\right) E U^{\prime}\left(A_{11}+A_{12}\right)+\frac{m_{4}}{m_{3}+m_{4}} \\
& \cdot\left(-\alpha_{13}+\alpha_{12}\right) E U^{\prime} A_{13}=0 .
\end{aligned}
$$

Solving the above set of equations for $m_{1}, m_{2}, m_{3}$, and $m_{4}$ and substituting values into $\left(m_{1} / m_{1}+m_{2}\right),\left(m_{2} / m_{1}+m_{2}\right)$, $\left(m_{3} / m_{3}+m_{4}\right)$, and $\left(m_{4} / m_{3}+m_{4}\right)$, we obtain

$$
\begin{aligned}
& \zeta_{1}=\frac{m_{1}}{m_{1}+m_{2}}=\frac{A_{23}+A_{3}}{A_{21}+A_{22}+A_{23}+A_{3}}, \\
& \zeta_{2}=\frac{m_{2}}{m_{1}+m_{2}}=\frac{A_{21}+A_{22}}{A_{21}+A_{22}+A_{23}+A_{3}}, \\
& \zeta_{3}=\frac{m_{3}}{m_{3}+m_{4}}=\frac{A_{13}}{A_{11}+A_{12}+A_{13}}, \\
& \zeta_{4}=\frac{m_{4}}{m_{3}+m_{4}}=\frac{A_{11}+A_{12}}{A_{11}+A_{12}+A_{13}},
\end{aligned}
$$

where $\zeta_{k}(k=1, \ldots, 4)$ is the constant value defined as the correction factor. $A_{i j}=2 b_{i j} t_{i j}(i=1,2, j=1, \ldots, \zeta$, and $i=3)$ is the area of flanges, as shown in Figure 1.

Now, from the equilibrium condition,

$$
\int_{A} \sigma_{x} \mathrm{~d} A=0
$$

which must be satisfied since there is no axial force present, that is, $N_{x}=0$. Through substituting equations (1), (4), and (23a) into equation (28), we noticed that equation (28) cannot be fulfilled as the coefficients of the shear lag warping functions, $\alpha_{i j}$, are given without considering the internal force balance. Therefore, to satisfy equation (28), one more correction term, $D U(x)$, should be introduced in equation (1), and the expression of equation (1) can be further rewritten as

$$
u_{i j}=u_{\mathrm{SL}, i j}(x, y)+u_{\phi, r}(x, y)+D U(x),
$$

where $D$ is the internal force balance factor, which can be obtained from equation (28).

2.4. Initial Shear Deformation $\gamma_{03}$. According to equation (9), at those positions of shear flow which is equal to zero, the first derivative of the shear lag warping displacement with respect to $y$ is zero, owing to the continuous condition for shear lag warping displacement function, and the shear flow in the opposite direction plays a role as constraints, and the shear deformation nearby is limited. However, for those shear flows which are zero at the open-end flanges, lacking the constraint nearby, hence, the shear deformation nearby cannot be limited, and the first derivative of shear lag warping displacement is no more zero. Instead, a shear deformation exists, which is constant through the top lateral cantilever flanges and can be further defined as the initial shear deformation, $\gamma_{03}$, as illustrated in Figure 3.

Let

$$
\alpha_{30}=\frac{\int_{0}^{b_{3}} \gamma_{x y}(y) \mathrm{d} y}{\int_{0}^{b_{21}} \gamma_{x y}(y) \mathrm{d} y} .
$$

Then, the coefficient of shear lag warping function in the top lateral cantilever flange, $\alpha_{3}$, can be rewritten from equation (12), that is, 


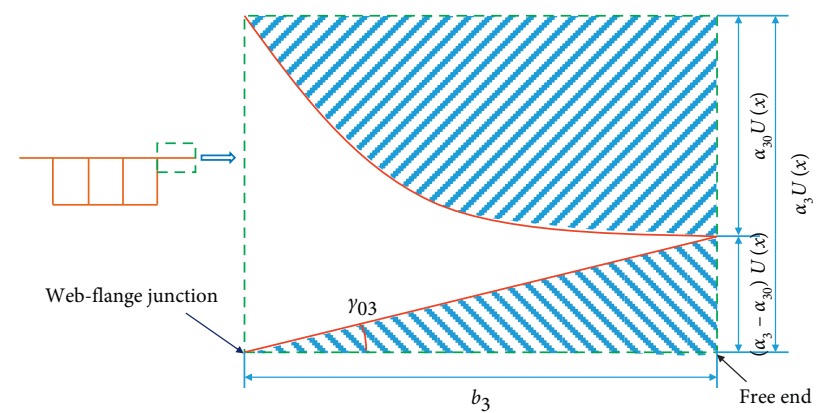

FIgURE 3: Initial shear deformation in the top lateral cantilever flange.

$$
\alpha_{3}=\frac{\int_{0}^{b_{3}} \gamma_{x y}-\gamma_{03} \mathrm{~d} y}{\int_{0}^{b_{21}} \gamma_{x y} \mathrm{~d} y}=\alpha_{30}-\frac{\gamma_{03} b_{3}}{\int_{0}^{b_{21}} \gamma_{x y} \mathrm{~d} y}
$$

The substitution of equations (11) and (13) into equation (31) yields the initial shear deformation $\gamma_{03}$ regarding to the function $U(x)$ :

$$
\gamma_{03} \frac{\left(\alpha_{3}-\alpha_{30}\right) \alpha_{21}}{b_{3}} U(x)
$$

Because the value of initial shear deformation, $\gamma_{03}$, is constant, the additional longitudinal warping displacement in the top lateral cantilever flanges can be expressed as

$$
u_{3 a}=-\Delta u_{3 a}\left(1-\frac{y}{b_{3}}\right), \quad 0 \leq y \leq b_{3},
$$

where

$$
\Delta u_{3 a}=\gamma_{03} b_{3}=\left(\alpha_{3}-\alpha_{30}\right) \alpha_{21} U(x) \text {. }
$$

Consequently, the longitudinal warping displacement in the top lateral cantilever flanges consists of four parts: shear lag warping displacement contribution, internal force balance contribution, initial shear deformation contribution, and bending contribution. Since the initial shear deformation $\left(\gamma_{03}\right)$ and the coefficient $\left(\alpha_{3}\right)$ of the shear lag warping function in the top lateral cantilever flange are undetermined and cannot be given directly, it is suggested that, for simplicity, the distribution of warping displacement due to the initial shear deformation contribution can be regarded as the same as the transverse distribution function $\psi_{i j}(y)$. Equation (33a) can be easily expressed as

$$
u_{3 a}=\Delta u_{3 a} \psi_{3}, \quad 0 \leq y \leq b_{3} .
$$

As a result, the initial shear deformation contribution and shear lag warping contribution can be combined and reduced to $\alpha_{3} \psi_{3} U(x)$; once the coefficient $\left(\alpha_{3}\right)$ of the shear lag warping function in the top lateral cantilever flange is determined, the inverse process, equation (32), can be employed, and the initial shear deformation contribution can be separated.

2.5. Derivation of the Transverse Distribution Function of Longitudinal Warping Displacement $\psi_{i j}(y)$. According to the aforementioned conditions of the transverse distribution function $\psi_{i j}(y)$ given by equations (3a), (3b), and (10), the transverse distribution function $\psi_{i j}(y)$ can be assumed to be

$$
\psi_{i j}(y)=\left[1, x, x^{2}\right]\left[\begin{array}{l}
c_{1} \\
c_{2} \\
c_{3}
\end{array}\right],
$$

where the constants $c_{1}, c_{2}$, and $c_{3}$ can be determined from the substitution of the above equation into equations (3a), (3b), and (10).

The expression for the transverse distribution function $\psi_{i j}(y)$ can be given by

$$
\psi_{i j}(y)=1-\frac{y^{2}}{b_{i j}^{2}},
$$

where $b_{i j}(i=1, \ldots 2, j=1, \ldots, \zeta$, and $i=3)$ denotes the shear lag width of the flanges, as illustrated in Figure 1.

Also, it can be written in the form of a cosine function:

$$
\psi_{i j}(y)=\cos \left(\frac{\pi y}{2 b_{i j}}\right) .
$$

The transverse distribution function given in equation (36) is consistent with that reported in the companion papers $[1,2,12-15]$ and can also be expressed in the form of equation (37), similar as $[3-5,20]$.

Now, given the transverse distribution function at the web-flange junction $\left(y=b_{3}\right)$ is zero from equation ( $\left.3 \mathrm{~b}\right)$, the normal stress $\sigma_{x}$ and the shearing stress $\tau_{x y}$ acting on a small element $\mathrm{d} x \mathrm{~d} y$ should satisfy the equilibrium condition of stresses in the direction of $x$-axis, which gives the following differential equation [24]:

$$
\frac{\partial \sigma_{x}}{\partial x}+\frac{\partial \tau_{x y}}{\partial y}=0
$$

According to assumption 4, the substitution of equations (23a) and (29) into equation (38) yields

$$
E \frac{\partial^{2} u_{3}(x, y, z)}{\partial x^{2}}+G \frac{\partial^{2} \psi_{3}(y)}{\partial y^{2}} U_{3}(x)=0,
$$

where $E$ is Young's modulus.

As for equation (39) is identically equal to zero, equation (39) can be divided into two parts:

$$
\begin{array}{r}
\left.\frac{\partial^{2} \psi_{3}(y)}{\partial y^{2}}\right|_{y=b_{3}}=0, \\
\left.\frac{\partial^{2} u_{3}(x, y, z)}{\partial x^{2}}\right|_{y=b_{3}}=0,
\end{array}
$$

where equations (40a) and (40b) should be fulfilled simultaneously.

Compared with equation (36), only equation (37) can satisfy equation (40a) strictly, and finally, equation (37) is the most appropriate functional expression for describing the transverse distribution of the shear lag warping displacement function. 


\section{Formulation and Solution}

The total potential energy of the thin-walled single-box multicell box girder can be obtained by the summation of the strain energy of the flanges and webs and the external potential energy and also can be expressed as follows:

$$
\prod=\sum_{i j} U_{p, i j}+U_{p, w}+V_{p},
$$

where

The strain energy of flanges $\sum_{i j} U_{p, i j}(i=1, \ldots 2, j=1, \ldots$, $\zeta$, and $i=3)$ :

$$
\sum_{i j} U_{p, i j}=\sum_{i j} \int_{0}^{L}\left(\iint_{A_{i j}} \frac{1}{2}\left(\sigma_{i j} \varepsilon_{i j}+\tau_{i j} \gamma_{i j}\right) \mathrm{d} A\right) \mathrm{d} x .
$$

The strain energy of webs $U_{p, w}$ :

$$
U_{p, w}=\int_{0}^{L}\left(\iint_{A_{w}} \frac{1}{2}\left(\sigma_{w} \varepsilon_{w}+\tau_{w} \gamma_{w}\right) \mathrm{d} A\right) \mathrm{d} x .
$$

The external potential energy $V_{p}[3]$ :

$$
V_{p}=-\int_{0}^{L} q(x) w(x) \mathrm{d} x=\int_{0}^{L} M(x) w^{\prime \prime}(x) \mathrm{d} x-\left.M(x) \beta(x)\right|_{x_{1}} ^{x_{2}},
$$

where $\prod$ is the total potential energy, $M(x)$ is the bending moment, and $w^{\prime \prime}(x)$ is the second derivative of the deflection of the girder with respect to $x$.

3.1. Fundamental Governing Differential Equations. The governing differential equations can be derived by using the principle of minimum potential energy [25]:

$$
\delta \prod=0 .
$$
obtain

By substituting equation (41) into equation (43), we

$$
\begin{array}{r}
w^{\prime \prime}(x)-\beta^{\prime}(x)+a_{1} U^{\prime}(x)+\frac{M(x)}{E I_{y}}=0, \\
a_{2} U(x)-a_{2} U^{\prime \prime}(x)-a_{2}\left(w^{\prime \prime \prime}(x)-\beta^{\prime \prime}(x)\right)=0,
\end{array}
$$

and the natural boundary condition:

$$
a_{3} U^{\prime}(x)+a_{4}\left(w^{\prime \prime}(x)-\beta \prime(x)\right)=0,
$$

where

$$
\begin{aligned}
& a_{1}=\frac{\operatorname{collect}\left(\partial F / \partial w^{\prime \prime}, U^{\prime}\right)}{\operatorname{collect}\left(\partial F / \partial w^{\prime \prime}, w^{\prime \prime}\right)}, \\
& a_{2}=\operatorname{collect}\left(\frac{\partial F}{\partial U}, U\right)
\end{aligned}
$$

$$
\begin{aligned}
& a_{3}=\text { collect }\left(-\frac{\partial}{\partial x}\left(\frac{\partial F}{\partial U^{\prime}}\right), U^{\prime \prime}\right), \\
& a_{4}=\text { collect }\left(-\frac{\partial}{\partial x}\left(\frac{\partial F}{\partial U^{\prime}}\right), w^{\prime \prime \prime}\right) .
\end{aligned}
$$

According to equations (44a) and (44b), the two unknown generalized displacements $w(x)$ and $U(x)$ are coupled; hence, the two variables need to be decoupled and analyzed as differential equations independently.

To this end, the differential equation for the normalized shear lag warping function $U(x)$ can now be determined by differentiating equation (44a) with respect to $x$ and substituting into equation (44b). By eliminating the term $w^{\prime \prime \prime}(x)-\beta^{\prime \prime}(x)$ from equation (44b), the following differential equation is obtained:

$$
U(x)^{\prime \prime}-k^{2} U(x)=n \frac{M^{\prime}(x)}{E I_{y}}
$$

where

$$
\begin{gathered}
k^{2}=\frac{a_{2}}{a_{3}-a_{1} a_{4}}, \\
n=\frac{a_{4}}{a_{3}-a_{1} a_{4}} .
\end{gathered}
$$

From equation (46), we can arrive at the conclusion that the shear deformation considered in webs will not affect the function $U(x)$.

Once the normalized shear lag warping function $U(x)$ is determined, the differential equation for the deflection of the girder $w(x)$ can be written in the form

$$
w^{\prime \prime}(x)=\beta^{\prime}(x)-a_{1} U^{\prime}(x)-\frac{M(x)}{E I_{y}},
$$

where $I_{y}$ is the geometric moment of inertia with respect to the $y$-axis.

Finally, equations (46) and (48) can be solved with the associated load and boundary conditions as follows:

For a fixed end: $U=0, w=0, w^{\prime}-\beta=0$

For a simply supported end: $U^{\prime}=0, w=0$

3.2. Designed Procedure of the Coefficient of Shear Lag Warping Function $\alpha_{3}$. Although the initial shear deformation $\left(\gamma_{03}\right)$ plays an important role in the shear lag effect in the top lateral cantilever flange, there is a lack of an appropriate method to solve it directly. However, the proposition described in equation (40b) is a powerful approach for solving the coefficient of shear lag warping function $\left(\alpha_{3}\right)$ and can be performed by a computer program, as outlined by the flowchart in Figure 4.

In this flowchart, it should be noted that the modification on the continuity of shear lag warping displacement function is not taken into account as the boundary condition for top lateral cantilever flanges should not be affected by the 


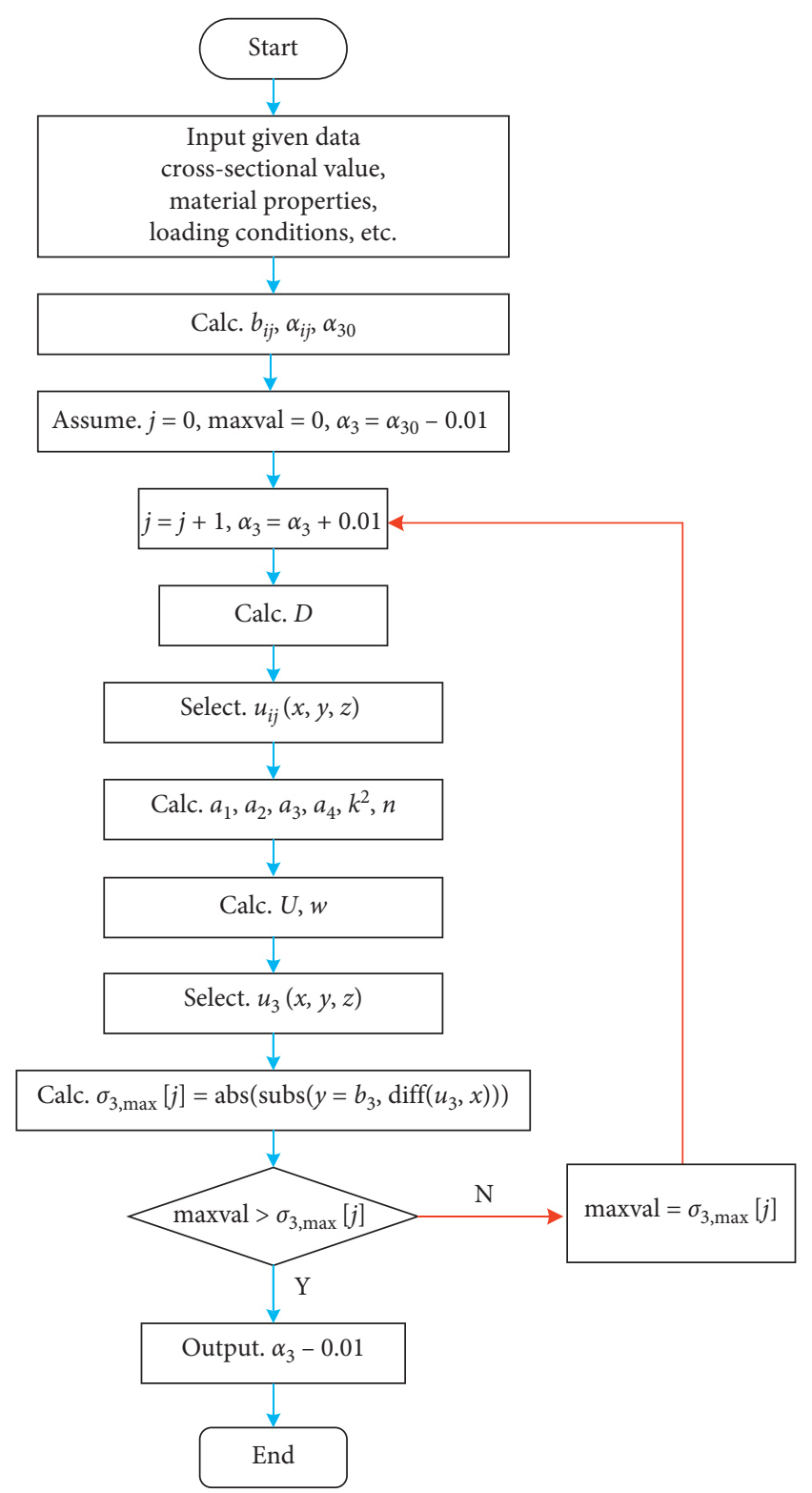

FIGURE 4: Flowchart of the coefficient of shear lag warping function $\alpha_{3}$.

parameter $m_{1}, m_{2}, m_{3}$, and $m_{4}$. Hence, the correction factors $\left(\xi_{k}\right)$ are given as zero.

3.3. Modification of Normal Stress Distribution through Top Lateral Cantilever Flanges. Since the value of the coefficient of shear lag warping function $\left(\alpha_{3}\right)$ can be derived from the designed procedure, as illustrated in Figure 4, the final normal stress distribution can be obtained accordingly. However, because the initial shear deformation contribution from the longitudinal warping displacement is assumed to be a cosine function, the normal stress distribution calculated in the top lateral cantilever flanges will be less than the actual stress. Therefore, the influence of the initial shear deformation contribution on the normal stress distribution should be analyzed independently.
On the basis of assumption 4, the normal stress difference in the top lateral cantilever flanges can be given by

$$
\Delta \sigma_{3}=\alpha_{3} E U(x)^{\prime}
$$

In a similar manner, the following additional normal stress difference function is obtained due to the initial shear deformation contribution:

$$
\Delta \sigma_{3 a}=\left(\alpha_{3}-\alpha_{30}\right) \alpha_{21} E U^{\prime}(x) .
$$

The additional normal stress difference, $\Delta \sigma_{3 a}$, can be determined by substituting equation (49) into equation (50); eliminating the term $E U^{\prime}(x)$ from equation (50), then equation (50) can be reduced to

$$
\Delta \sigma_{3 a}=\left(\alpha_{3}-\alpha_{30}\right) \alpha_{21} \frac{\Delta \sigma_{3 a}}{\alpha_{3}} .
$$

And the normal stress difference due to shear lag contribution can be reduced to

$$
\Delta \sigma_{30}=\frac{\alpha_{30}}{\alpha_{3}} \Delta \sigma_{3}
$$

As a result, the normal stress distribution on the top lateral cantilever flanges can be rewritten as

$$
\sigma_{3}(x, y)=\left.\sigma_{3}\right|_{y=b_{3}}-\psi \Delta \sigma_{30}-\left(1-\frac{y}{b^{3}}\right) \Delta \sigma_{3 a} .
$$

\section{The Finite Element Method}

The currently available data regarding shear lag analysis in thin-walled single-box multicell box girders are very limited, while the finite element method (FEM) can be quite useful in providing additional data for comparison with the results with those obtained analytically from the proposed method. In order to further verify the designed procedure and the proposed method, single-box two-cell (1B2C) and singlebox three-cell (1B3C) box girders under uniformly distributed load were performed by applying the FEM to provide more additional information, as illustrated in Figure 5.

The finite element analysis in this study was carried out using a computer program, ABAQUS, which can provide rich element types [26]. It should be mentioned that the solid part was modeled with the incompatible mode solid element (C3D8I), as shown in Figure 5, which can overcome the problem of shear locking in a fully integrated first-order element (C3D8) and can reach a high degree of accuracy as fully integrated second-order element (C3D20); more importantly, less elements are needed.

The beam's uniformly distributed load per unit length is modeled by applying pressure acting on the surface of the flange-web junction elements uniformly through the beam length, and the modulus of elasticity and Poisson ratio are 3,000 $\mathrm{MPa}$ and 0.385 , respectively.

Figure 6 shows the boundary conditions and load conditions that are used in the numerical models. 


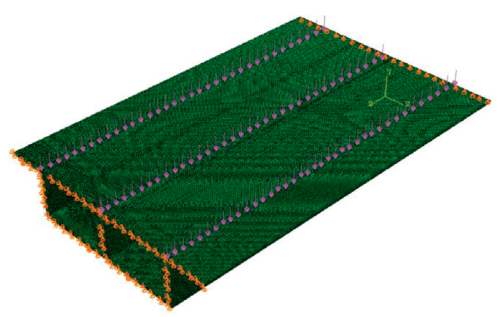

(a)

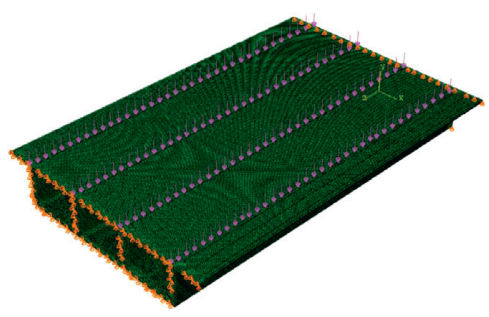

(b)

Figure 5: Schemes for the FE models: (a) meshing of the model of 1B2C; (b) meshing of the model of 1B3C.

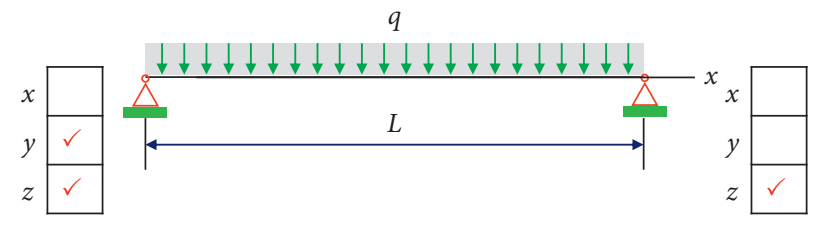

(a)

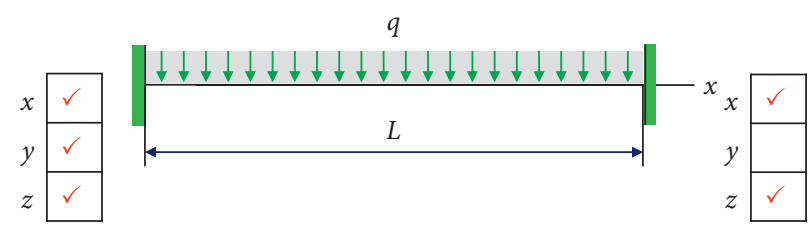

(b)

FiguRE 6: (a) Simply supported box girder subjected to uniformly distributed load. (b) Fixed-end box girder subjected to uniformly distributed load.

\section{Numerical Examples}

In order to illustrate the validity and efficiency of the proposed method on the analysis of the shear lag effect in the thin-walled single-box multicell box girder, four examples are provided in this section: for examples 1 and 2, the type of single-box two-cell (1B2C) box girders (simply supported and fixed end, as shown in Figure 6) are considered, and for examples 3 and 4, the type of single-box three-cell (1B3C) box girders (simply supported and fixed end, as shown in Figure 6) are considered.

The proposed methods, SL-THY1 (short for shear lag effect analysis without considering the influence of initial shear deformation in top lateral cantilever flanges, where $\alpha_{3}=\alpha_{30}$ ) and SL-THY2 (short for shear lag effect analysis considering the influence of initial shear deformation in top lateral cantilever flanges, where $\alpha_{3} \neq \alpha_{30}$ ), are applied to the simple structural scheme of the simply supported beam and of the fixed-end beam under the uniformly distributed load, with the aim of underlying the importance of the designed procedure and the proposed method, and the comparison to the results with those obtained from the aforementioned computer program, ABAQUS, is conducted.

5.1. Example 1. In this example, a thin-walled single-box two-cell box girder (simply supported) as shown in Figure 6(a), with a span length of $900 \mathrm{~mm}$ subjected to a uniformly distributed load $q=9 \mathrm{~N} / \mathrm{mm}$ along the span length, is being examined. The dimensions of the cross section of the single-box two-cell box girder are shown in Figure 7. The material properties used in the theoretical analysis are the same as those used in finite element models.
Figure 5(a) shows an example of the finite element model of a single-box two-cell box girder. Finite element models are made in Abaqus/Standard and used in a sensitivity study to investigate the influence of element size on the predictions of the shear lag effect. Based on the sensitivity study, several simulations of example 1 are performed using a randomly generated mesh of hexahedral solid element (C3D8I), and the results of which show that the normal stresses derived at the designated measure points $(\mathrm{M} 1 \sim \mathrm{M} 7)$, as illustrated in Figure 7 , have no obvious changes with the increase of the number of elements; according to Figure 8, and furthermore, the mesh insensitivity of the number of elements on the shear lag effect can be demonstrated. Hence, the flanges are meshed uniformly by $3 \times 3 \times 3 \mathrm{~mm}$ hexahedral solid element (C3D8I), and the webs are meshed uniformly by $4 \times 3 \times 3 \mathrm{~mm}$ hexahedral solid element (C3D8I), and finally, $24.78 \times 10^{4}$ solid elements are used in the finite element analysis.

The parameters, including the shear lag widths of flanges $b_{i j}(i=1, \ldots, 2, j=1, \ldots, 2$, and $i=3)$, the coefficients of shear lag warping functions $\alpha_{i j}(i=1, \ldots, 2, j=1, \ldots, 2$, and $i=3)$, shear factor $\alpha$, and the correction factors $\zeta_{k}(k=1, \ldots, 4)$, for shear lag effect analysis in the thin-walled single-box two-cell box girder are listed in Table 1.

Figure 9 shows the comparison of the shear lag coefficients predicted by the proposed method (SL-THY1 and SLTHY2) and FEM analysis at the midspan and 1/3-span cross section of a simply supported box girder (1B2C). From the diagram, it is observed that the shear lag coefficient distributions predicted by the SL-THY2 analysis are preferred to those predicted by the SL-THY1 analysis, comparing with the FEM calculation. These results suggest that the initial shear deformation $\left(\gamma_{03}\right)$ in the top lateral cantilever flanges, indeed, exists and play an important role in affecting the shear lag coefficient distribution in the flanges. In the 


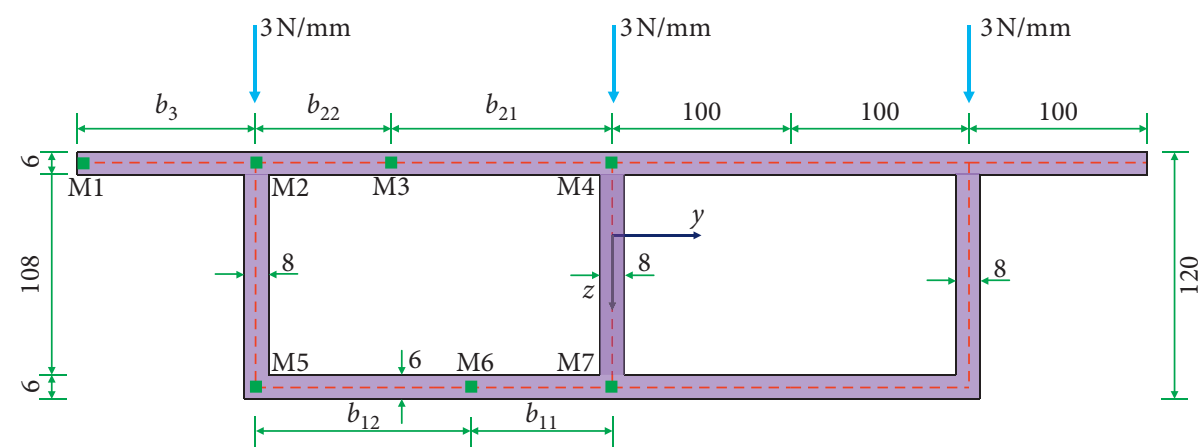

FIgURE 7: Cross section of the single-box two-cell box girder (unit: mm).

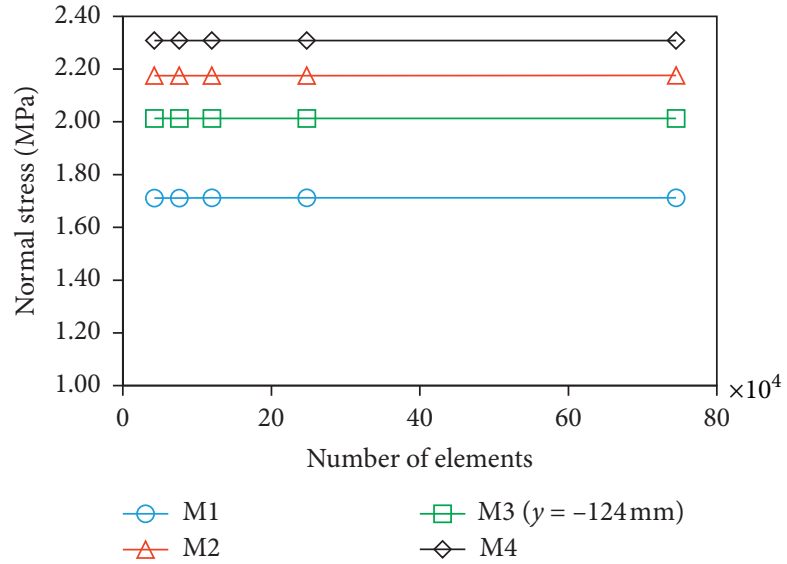

(a)

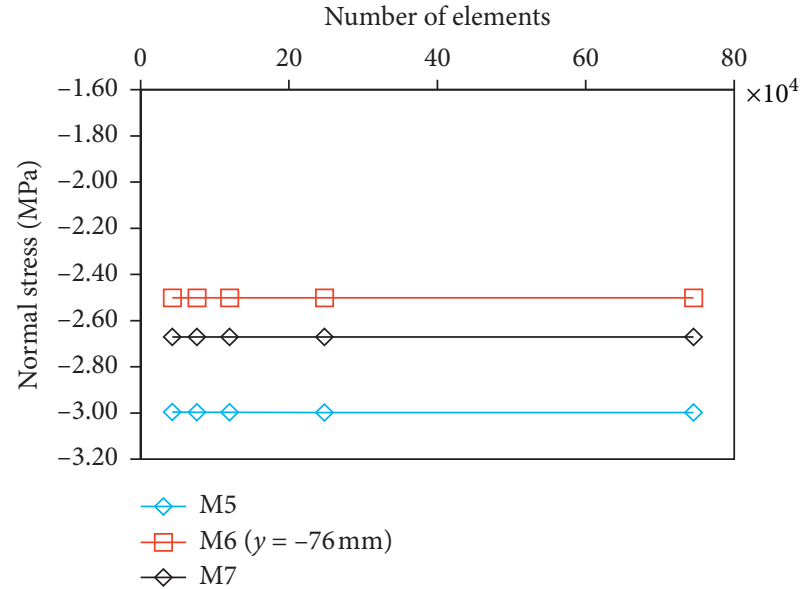

(b)

Figure 8: Sensitive analysis of the number of finite elements. (a) Measure points in top flanges of midspan cross section. (b) Measure points in bottom flanges of midspan cross section.

TABLe 1: Parameters for shear lag effect analysis in the thin-walled single-box two-cell box girder.

\begin{tabular}{ccccccccccccccccc}
\hline & $b_{11}(\mathrm{~mm})$ & $b_{12}(\mathrm{~mm})$ & $b_{21}(\mathrm{~mm})$ & $b_{22}(\mathrm{~mm})$ & $b_{3}(\mathrm{~mm})$ & $\alpha_{11}$ & $\alpha_{12}$ & $\alpha_{21}$ & $\alpha_{22}$ & $\alpha_{30}$ & $\alpha_{3}$ & $\alpha$ & $\xi_{1}$ & $\xi_{2}$ & $\xi_{3}$ & $\xi_{4}$ \\
\hline $1 \mathrm{~B} 2 \mathrm{C}$ & 77 & 123 & 113 & 87 & 100 & 0.60 & 1.56 & 1.00 & 0.58 & 0.78 & 1.26 & 1.19 & 0.622 & 0.378 & 0.616 & 0.384 \\
\hline
\end{tabular}

meantime, the influence of initial shear deformation can be well predicted by the designed procedure, as illustrated in Figure 4.

Besides, the most telling features of the charts are the dominance of accurate prediction of shear lag coefficient distribution in top and bottom central flanges by the SLTHY2 analysis, which may serve to explain the shear lag widths of flanges based on the bending shear flow distribution and the transverse distribution of shear lag warping displacement based on the function of cosine which are reasonable to those from FEM calculation.

Figure 10 shows the comparison of the vertical deflections predicted by the proposed methods (SL-THY1 and SLTHY2), Euler-Bernoulli beam theory (EBT), Timoshenko beam theory (TBT), and FEM calculation for a simply supported girder (1B2C). It is observed that the results of the proposed methods (SL-THY1 and SL-THY2) are in good agreement with those obtained by FEM calculation.

Table 2 lists the midspan and 1/3-span deflections of a simply supported box girder $(1 \mathrm{~B} 2 \mathrm{C})$ predicted by the proposed methods (SL-THY1 and SL-THY2), EBT, TBT, and FEM calculations. It can be seen that the maximum error of vertical deflection between EBT and FEM analysis may reach $-28.10 \%$, and minus indicates that the vertical deflection obtained from EBT is lower than FEM analysis. However, by considering the influence of shear lag effect and shear deformation on webs, the error of vertical deflection between SL-THY2 and FEM analysis can be reduced to $1.67 \%$. Hence, the contribution of shear lag effect and shear deformation to webs on the deflection of the box girder is remarkable on the 


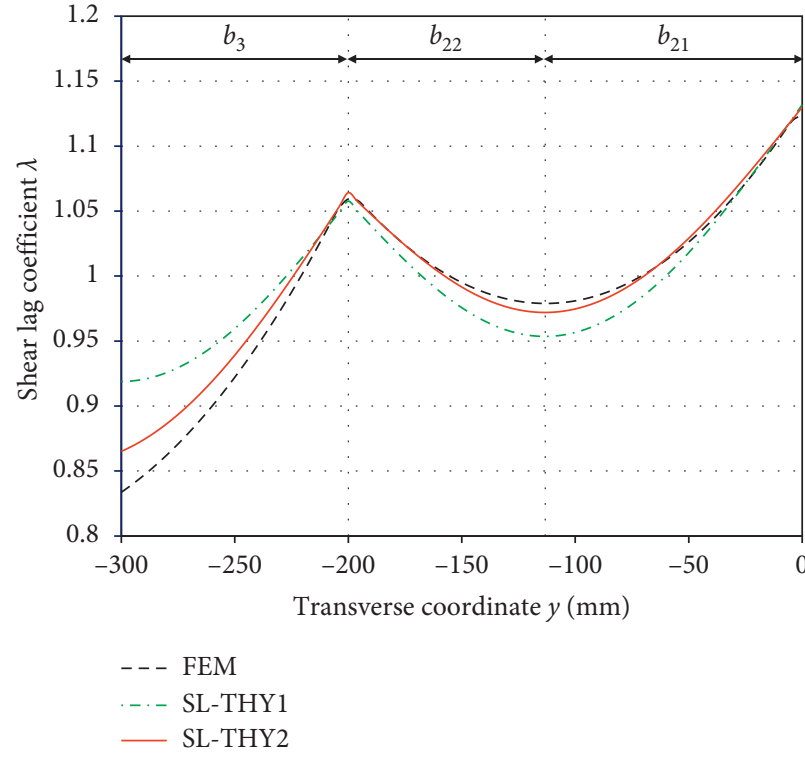

(a)

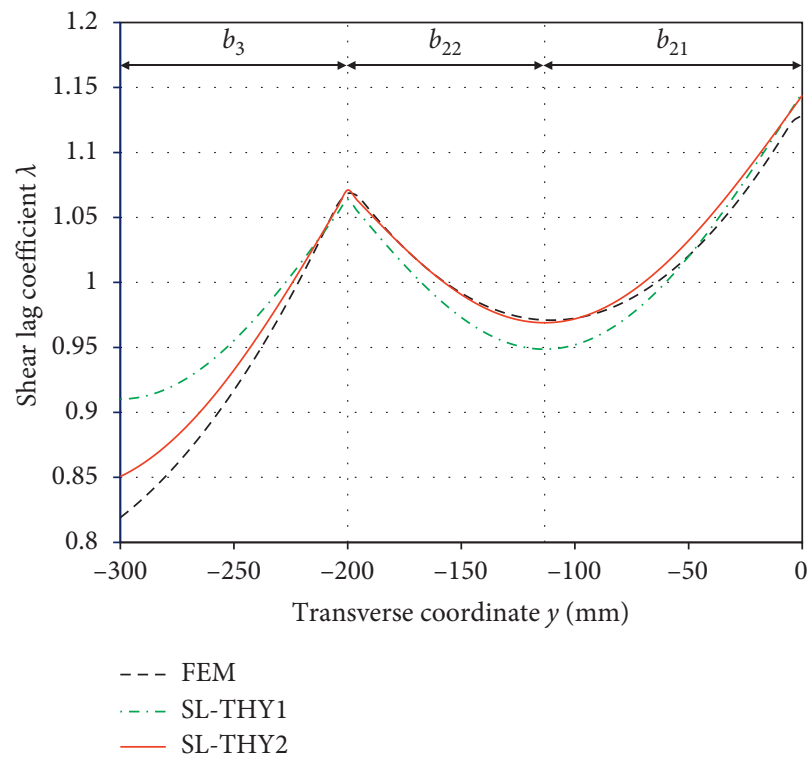

(c)

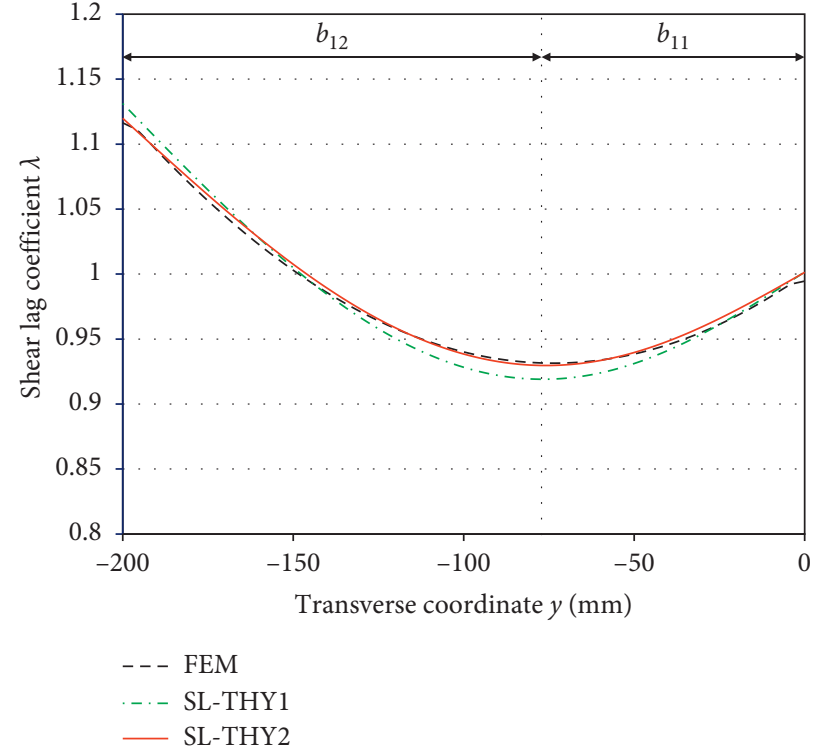

(b)

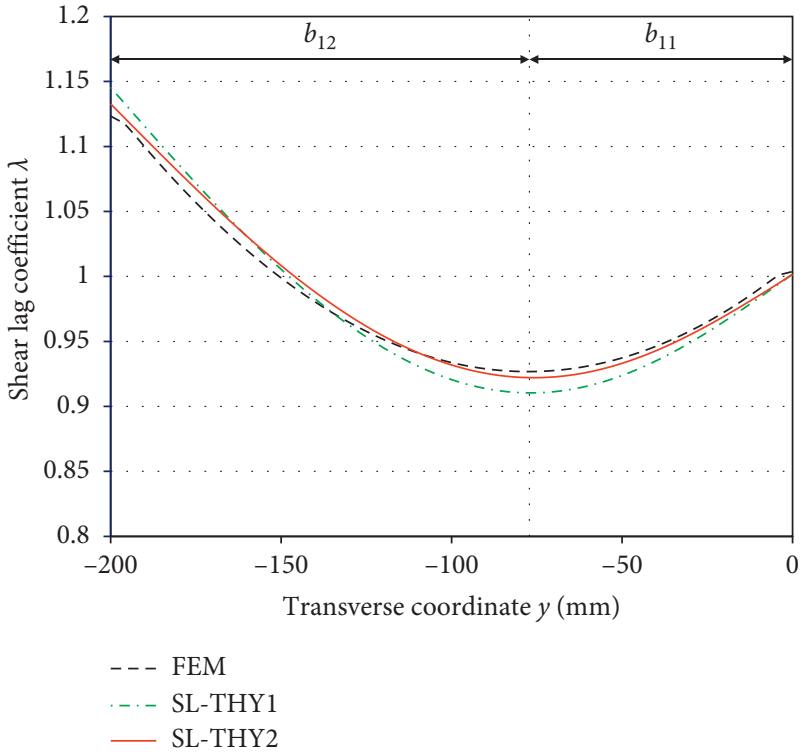

(d)

Figure 9: Shear lag coefficients of the simply supported box girder. (a) Top flanges of midspan cross section ( $x=450 \mathrm{~mm}$ ). (b) Bottom flanges of midspan cross section $(x=450 \mathrm{~mm})$. (c) Top flanges of $1 / 3$-span cross section $(x=300 \mathrm{~mm})$. (d) Bottom flanges of $1 / 3$-span cross section $(x=300 \mathrm{~mm})$.

whole and should be taken into account in engineering practice.

5.2. Example 2. In this example, a thin-walled single-box two-cell box girder (fixed end, as shown in Figure 6(b)), with a span length of $1,500 \mathrm{~mm}$ subjected to a uniformly distributed load $q=9 \mathrm{~N} / \mathrm{mm}$ along the span length, is being analyzed. The dimensions of the cross section of the singlebox two-cell box girder, material properties, and the parameters for shear lag effect analysis in the example are the same as those used in example 1.

Figure 11 compares the shear lag coefficient distribution predicted by the proposed method (SL-THY1 and SLTHY2) with that obtained using FEM analysis at the midspan and 2/5-span cross section of the fixed-end box girder (1B2C). The comparison shows that the shear lag coefficient distributions predicted by SL-THY2 correspond to the calculations obtained on the basis of the FEM calculation than those predicted by SL-THY1. 


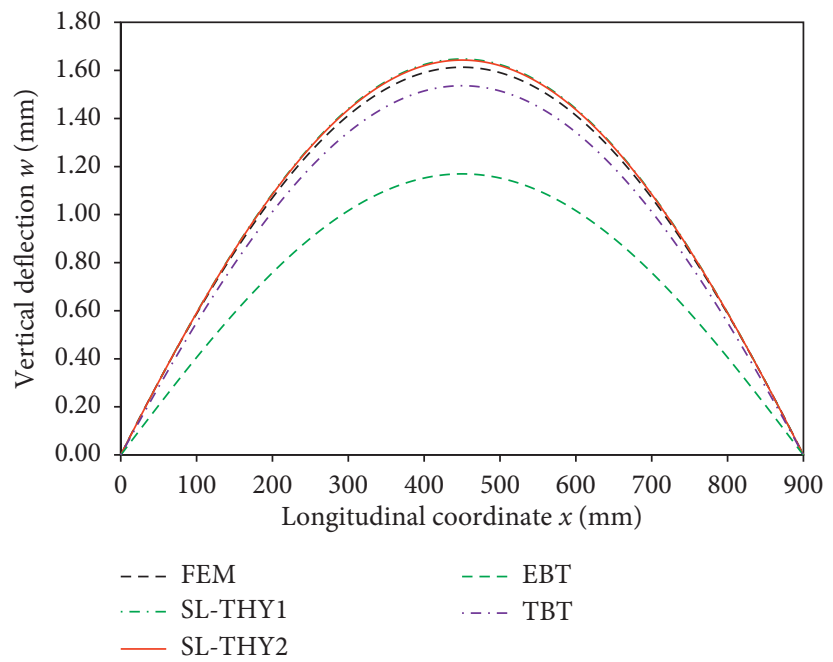

FIGURE 10: Comparison of vertical deflections predicted by the proposed methods (SL-THY1 and SL-THY2), EBT, TBT, and FEM analysis for the simply supported box girder (example 1).

TABLE 2: Vertical deflections of midspan and 1/3-span of a simply supported box girder (1B2C).

\begin{tabular}{|c|c|c|c|c|c|c|}
\hline \multicolumn{2}{|c|}{$x$} & FEM & EBT & TBT & SL-THY1 & SL-THY2 \\
\hline \multirow{2}{*}{$\mathrm{L} / 2(450 \mathrm{~mm})$} & $w(\mathrm{~mm})$ & 1.613 & 1.169 & 1.536 & 1.647 & 1.643 \\
\hline & Error (\%) & - & -27.54 & -4.77 & 2.09 & 1.84 \\
\hline \multirow{2}{*}{$\mathrm{L} / 3(300 \mathrm{~mm})$} & $w(\mathrm{~mm})$ & 1.413 & 1.016 & 1.343 & 1.440 & 1.437 \\
\hline & Error (\%) & - & -28.10 & -4.99 & 1.92 & 1.67 \\
\hline
\end{tabular}

Figure 12 compares the vertical deflections predicted by the proposed methods (SL-THY1 and SL-THY2), EBT, TBT, and FEM calculation for the fixed-end girder (1B2C). The comparison shows good agreement between the proposed method (SL-THY1 and SL-THY2) and FEM calculations.

Table 3 presents the comparison of the proposed methods (SL-THY1 and SL-THY2), EBT, TBT, and FEM calculations for the vertical deflections of the fixed-end box girder, and the midspan and 2/5-span cross sections are selected for error analysis. From the table, it can be seen that considerable improvement can be achieved in the prediction accuracy when using SL-THY2, and the maximum error of vertical deflection between EBT and FEM can be reduced from $-41.21 \%$ to $1.8 \%$, which proves the high precision of SL-THY2 in predicting vertical deflections.

5.3. Example 3. In this example, a thin-walled single-box three-cell box girder (simply supported) as shown in Figure 6(a), with a span length of $1,200 \mathrm{~mm}$ subjected to a uniformly distributed load $q=12 \mathrm{~N} / \mathrm{mm}$ along the span length, is being analyzed. The dimensions of the cross section of the single-box three-cell box girder are shown in Figure 13. The material properties used in the theoretical analysis are the same as those used in the finite element model. Figure 5(b) shows an example of the finite element model of a single-box three-cell box girder, and $94.72 \times 10^{4}$ solid elements are used in the finite element analysis.

The parameters, including the shear lag widths of flanges $b_{i j}(i=1, \ldots, 2, j=1, \ldots, 3$, and $i=3)$, the coefficients of shear lag warping functions $\alpha_{i j}(i=1,2, j=1, \ldots, 3$, and $i=3)$, shear factor $\alpha$, and the correction factors $\zeta_{k}(k=1, \ldots, 4)$, for shear lag effect analysis in the thin-walled single-box three-cell box girder are listed in Table 4.

Figure 14 shows the comparison of the shear lag coefficients predicted by the proposed method (SL-THY1 and SL-THY2) and FEM analysis at the midspan and 3/8-span cross section of a simply supported box girder (1B3C). It can be seen that the shear lag coefficient distributions predicted by SL-THY2 agree quite well with those calculated by FEM, which not only prove the existence of the initial shear deformation in top lateral cantilever flanges but also demonstrate that the proposed method (SL-THY2) can well improve the prediction accuracy of shear lag coefficient distribution.

Figure 15 shows the comparison of the vertical deflections predicted by the proposed methods (SL-THY1 and SLTHY2), EBT, TBT, and FEM calculation for a simply supported girder (1B3C). It is observed that the results derived from the proposed methods (SL-THY1 and SL-THY2) coincide with those from FEM calculation. 


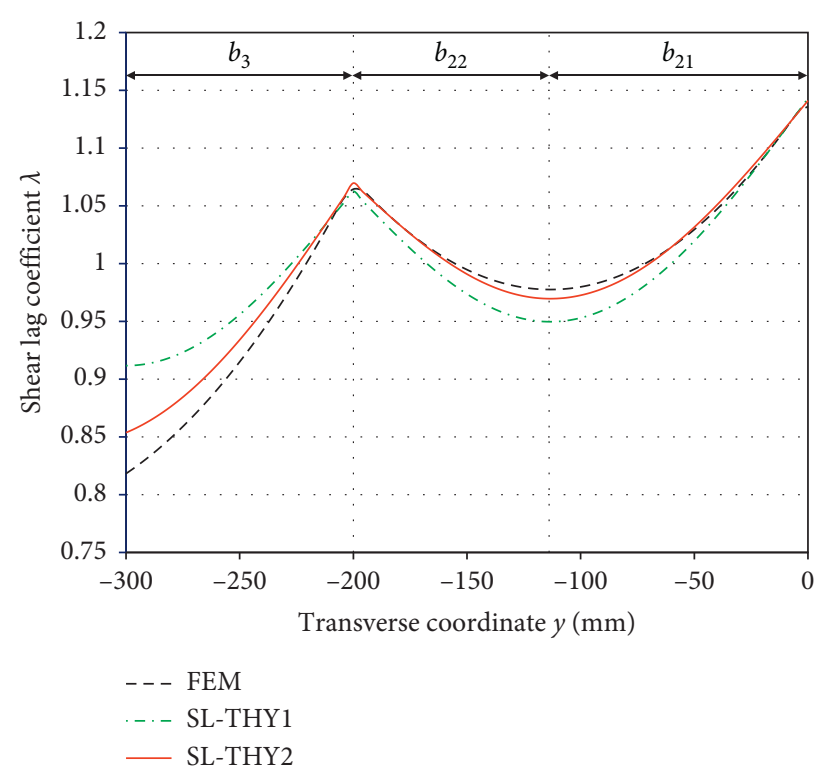

(a)

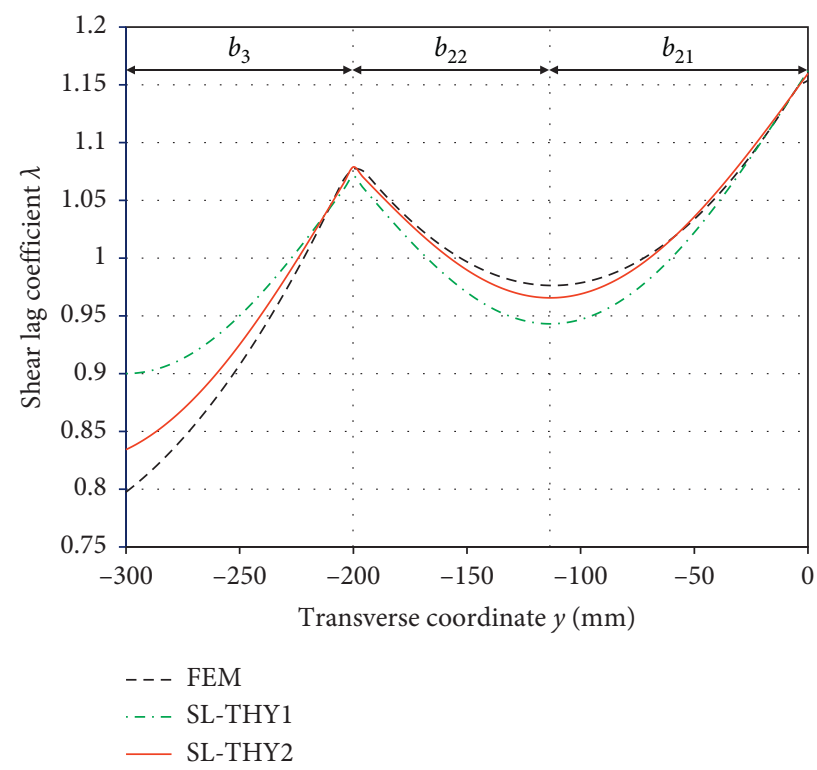

(c)

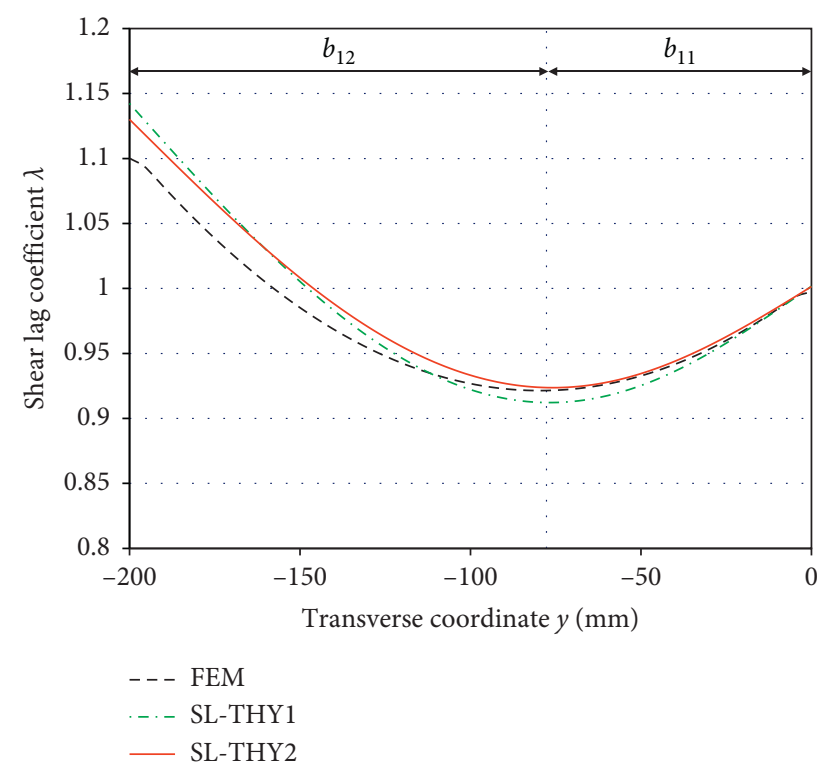

(b)

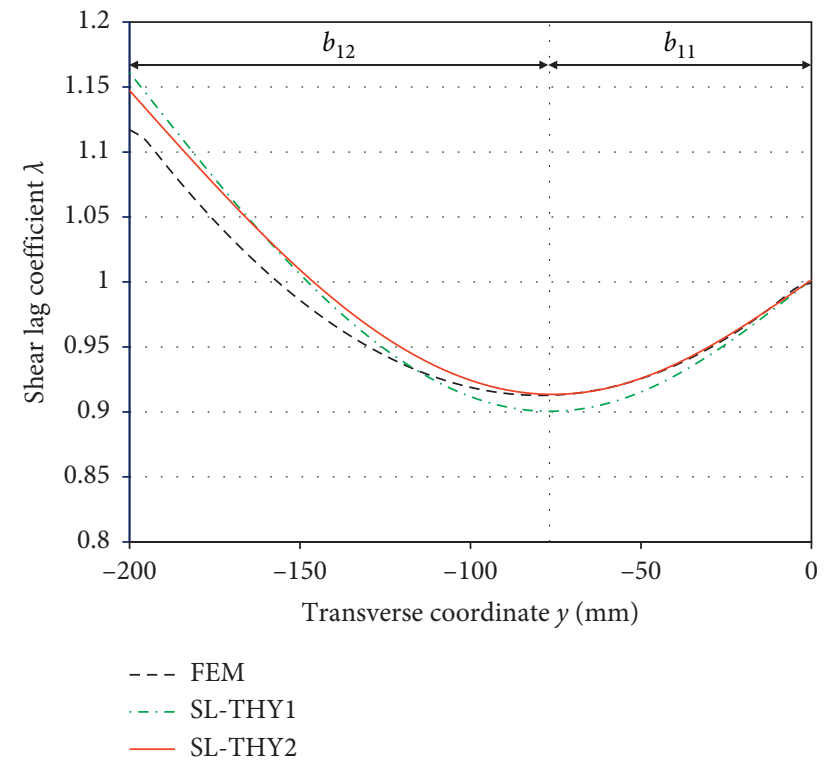

(d)

Figure 11: Shear lag coefficients of the fixed-end box girder. (a) Top flanges of midspan cross section ( $x=750 \mathrm{~mm}$ ). (b) Bottom flanges of midspan cross section $(x=750 \mathrm{~mm})$. (c) Top flanges of $2 / 5$-span cross section $(x=600 \mathrm{~mm})$. (d) Bottom flanges of $2 / 5$-span cross section $(x=600 \mathrm{~mm})$.

Table 5 shows the comparison of vertical deflections predicted by the proposed methods (SL-THY1 and SLTHY2), EBT, TBT, and FEM calculations for the simply supported box girder, and the midspan and 3/8-span cross sections are selected for error analysis. From the table, it is obvious that the maximum error of vertical deflection between EBT and FEM may reach $-21.08 \%$. However, by considering the shear lag effect and shear deformation in webs, the error of vertical deflection between SL-THY2 and FEM can be reduced to $0.67 \%$, which shows the high precision of SL-THY2 in predicting vertical deflection.
5.4. Example 4. In this example, a thin-walled single-box three-cell box girder (fixed end, as shown in Figure 6(b)), with a span length of $1,800 \mathrm{~mm}$ subjected to a uniformly distributed load $q=12 \mathrm{~N} / \mathrm{mm}$ along the span length, is being analyzed. The dimensions of the cross section of the singlebox three-cell box girder, material properties, and the parameters for shear lag effect analysis in the example are the same as those used in example 3.

Figure 16 compares the shear lag coefficient distribution predicted by the proposed methods (SL-THY1 and SLTHY2) with that obtained using FEM analysis at the midspan and 5/12-span cross section of the fixed-end box girder 


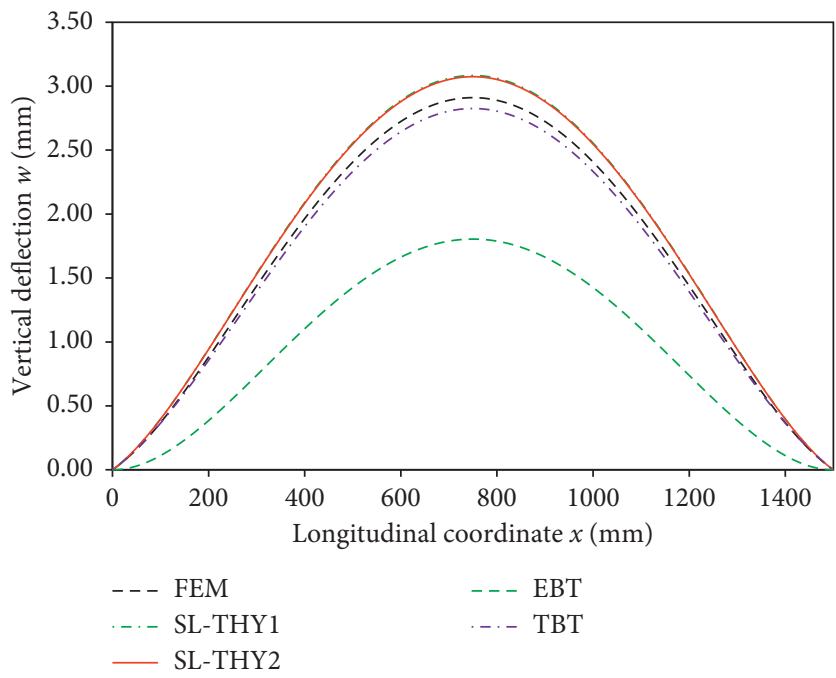

FIGURE 12: Comparison of vertical deflections predicted by the proposed methods (SL-THY1 and SL-THY2), EBT, TBT, and FEM analysis for the fixed-end box girder (example 2).

TABLe 3: Vertical deflections of midspan and 2/5-span of a simply supported box girder (1B2C).

\begin{tabular}{|c|c|c|c|c|c|c|}
\hline \multicolumn{2}{|c|}{$x$} & FEM & EBT & TBT & SL-THY1 & SL-THY2 \\
\hline \multirow{2}{*}{$\mathrm{L} / 2(750 \mathrm{~mm})$} & $w(\mathrm{~mm})$ & 3.029 & 1.804 & 2.825 & 3.084 & 3.074 \\
\hline & Error (\%) & 一 & -40.44 & -6.76 & 1.79 & 1.48 \\
\hline \multirow{2}{*}{$2 \mathrm{~L} / 5(600 \mathrm{~mm})$} & $w(\mathrm{~mm})$ & 2.828 & 1.663 & 2.642 & 2.888 & 2.879 \\
\hline & Error (\%) & - & -41.21 & -6.57 & 2.12 & 1.80 \\
\hline
\end{tabular}

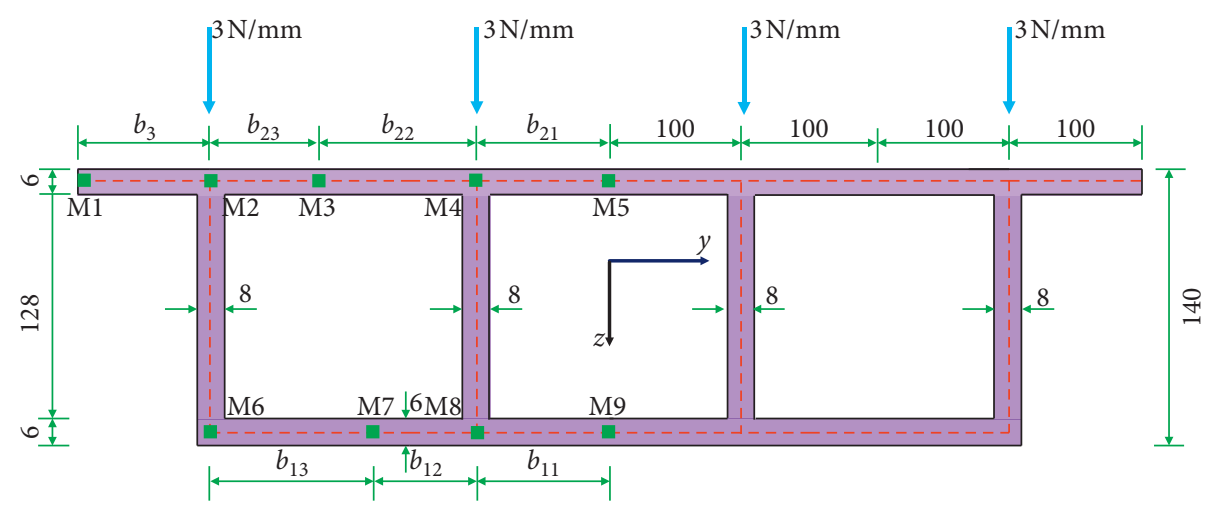

FIgURE 13: Cross section of the single-box three-cell box girder (unit: $\mathrm{mm}$ ).

Table 4: Parameters for shear lag effect analysis in the thin-walled single-box three-cell box girder.

\begin{tabular}{cccccccccccccccccccccc}
\hline & $\begin{array}{c}b_{11} \\
(\mathrm{~mm})\end{array}$ & $\begin{array}{c}b_{12} \\
(\mathrm{~mm})\end{array}$ & $\begin{array}{c}b_{13} \\
(\mathrm{~mm})\end{array}$ & $\begin{array}{c}b_{21} \\
(\mathrm{~mm})\end{array}$ & $\begin{array}{c}b_{22} \\
(\mathrm{~mm})\end{array}$ & $\begin{array}{c}b_{23} \\
(\mathrm{~mm})\end{array}$ & $\begin{array}{c}b_{3} \\
(\mathrm{~mm})\end{array}$ & $\alpha_{11}$ & $\alpha_{12}$ & $\alpha_{13}$ & $\alpha_{21}$ & $\alpha_{22}$ & $\alpha_{23}$ & $\alpha_{30}$ & $\alpha_{3}$ & $\xi_{1}$ & $\xi_{2}$ & $\xi_{3}$ & $\xi_{4}$ & - \\
\hline 1B3C & 100 & 67 & 133 & 100 & 120 & 80 & 100 & 1.21 & 0.54 & 2.15 & 1.00 & 1.44 & 0.64 & 1.00 & 1.56 & 0.450 & 0.550 & 0.445 & 0.555 & - \\
\hline
\end{tabular}

(1B3C). From the figures, it can be clearly seen that the shear lag coefficient distributions predicted by the SL-THY2 analysis are preferred to those predicted by the SL-THY1 analysis, comparing with the FEM calculation. Although there exists some discrepancy for SL-THY2 in predicting the shear lag coefficient distribution, the results obtained by SLTHY2 are in good agreement with the FEM calculations on the whole.

Figure 17 compares the vertical deflections predicted by the proposed methods (SL-THY1 and SL-THY2), EBT, TBT, 


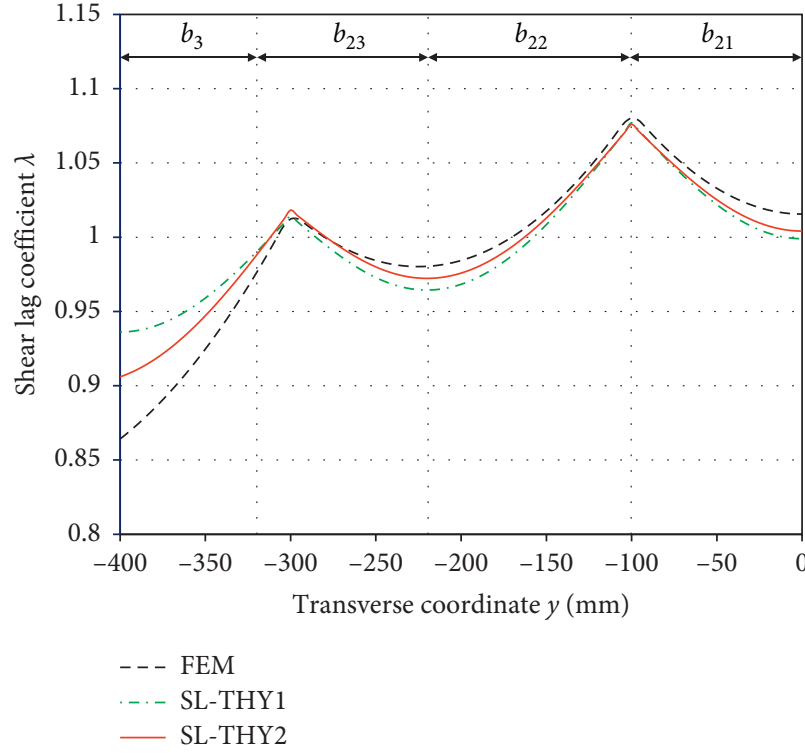

(a)

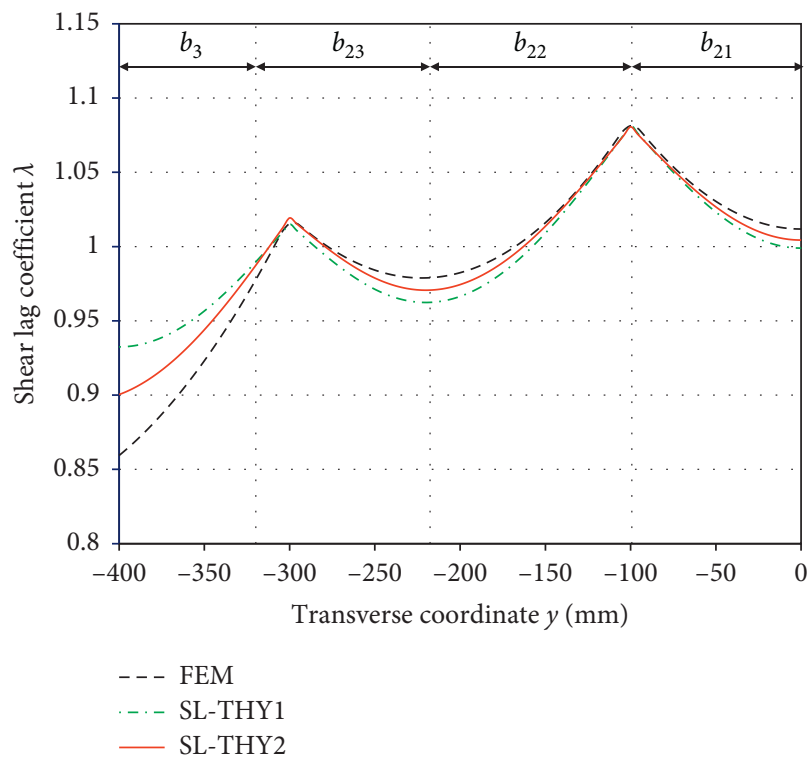

(c)

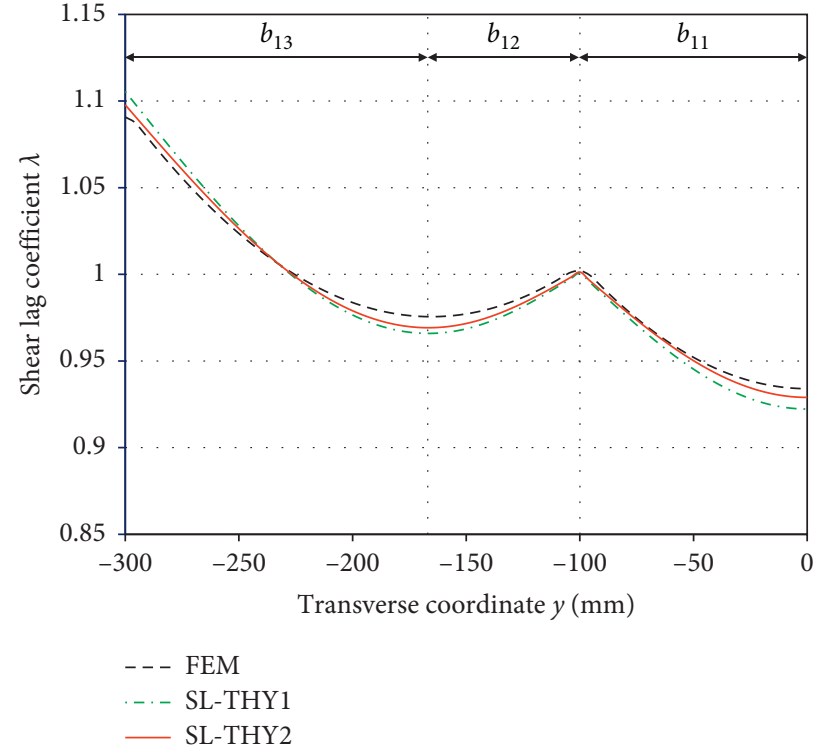

(b)

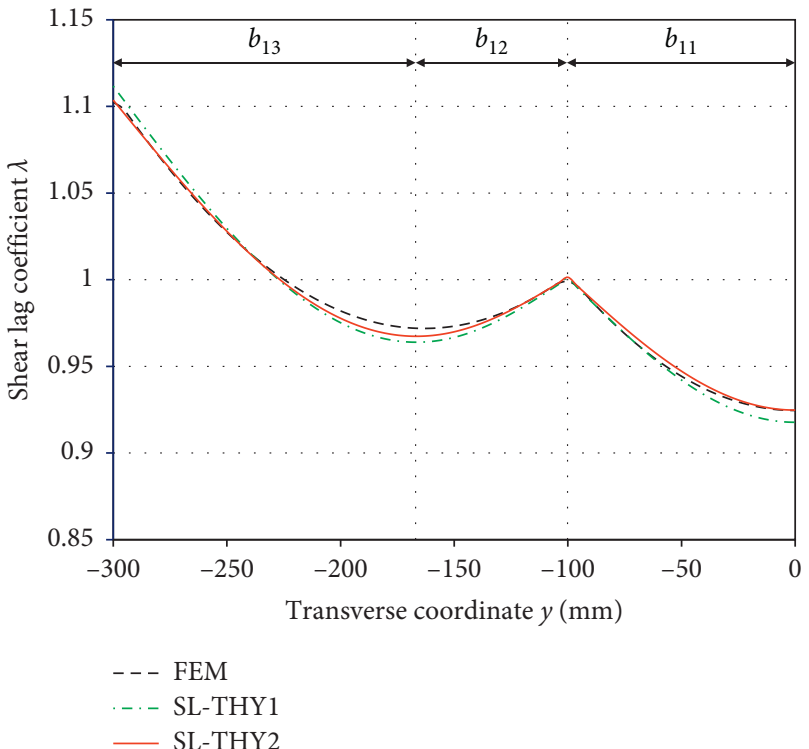

(d)

Figure 14: Shear lag coefficients of the simply supported box girder. (a) Top flanges of midspan cross section ( $x=600 \mathrm{~mm}$ ). (b) Bottom flanges of midspan cross section $(x=600 \mathrm{~mm})$. (c) Top flanges of $3 / 8$-span cross section $(x=450 \mathrm{~mm})$. (d) Bottom flanges of 3/8-span cross section $(x=450 \mathrm{~mm})$.

and FEM calculations for the fixed-end girder (1B3C). The results derived from the proposed methods (SL-THY1 and SL-THY2) match exactly to those obtained from FEM calculations.

Table 6 lists the comparison of the proposed methods (SL-THY1 and SL-THY2), EBT, TBT, and FEM calculation for the vertical deflections of the fixed-end box girder, and the midspan and 5/12-span cross sections are selected for error analysis. From the table, it can be seen that considerable improvement can be achieved in the prediction accuracy when using SL-THY2, and the maximum error of vertical deflection between EBT and FEM can be reduced from $-37.31 \%$ to $0.31 \%$, which shows the high precision of SL-THY2 in predicting vertical deflections. 


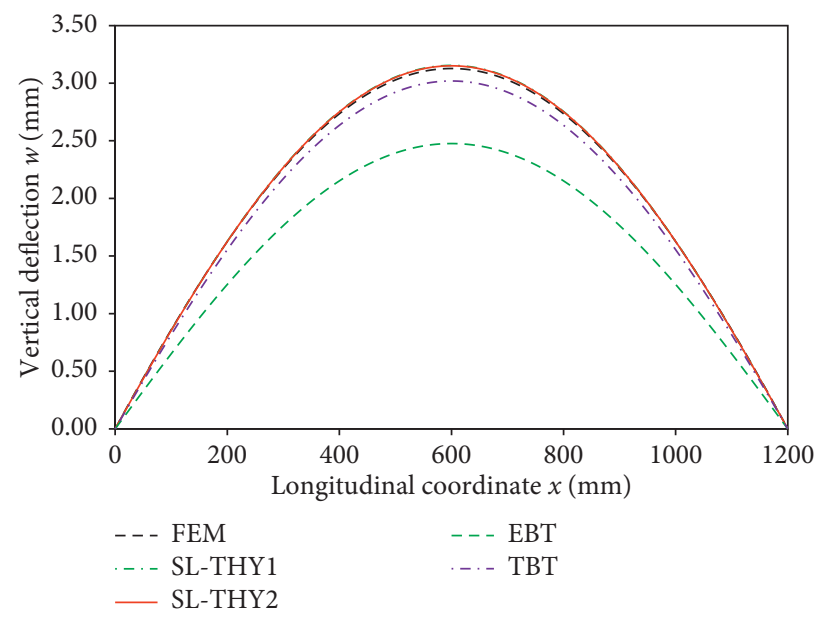

FIGURE 15: Comparison of vertical deflections predicted by the proposed methods (SL-THY1 and SL-THY2), EBT, TBT, and FEM analysis for the simply supported box girder (example 3).

TABLE 5: Vertical deflections of midspan and 3/8-span of a simply supported box girder (1B3C).

\begin{tabular}{|c|c|c|c|c|c|c|}
\hline \multicolumn{2}{|c|}{$x$} & FEM & EB & TB & SL-THY1 & SL-THY2 \\
\hline \multirow{2}{*}{$\mathrm{L} / 2(600 \mathrm{~mm})$} & $w(\mathrm{~mm})$ & 3.127 & 2.476 & 3.018 & 3.154 & 3.151 \\
\hline & Error (\%) & - & -20.81 & -3.48 & 0.85 & 0.75 \\
\hline \multirow{2}{*}{$3 \mathrm{~L} / 8(450 \mathrm{~mm})$} & $w(\mathrm{~mm})$ & 2.905 & 2.292 & 2.801 & 2.927 & 2.924 \\
\hline & Error (\%) & - & -21.08 & -3.59 & 0.77 & 0.67 \\
\hline
\end{tabular}

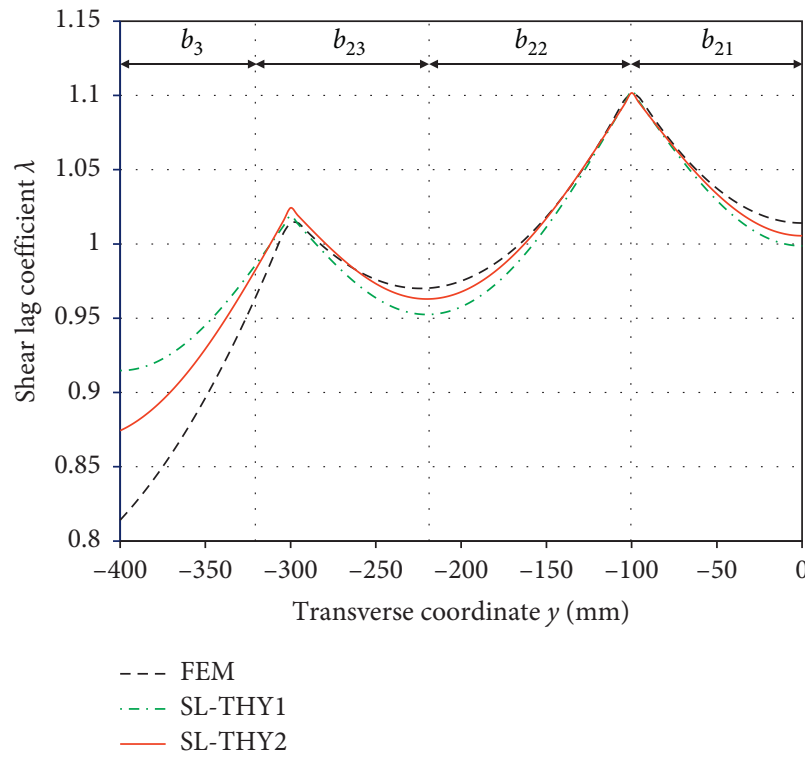

(a)

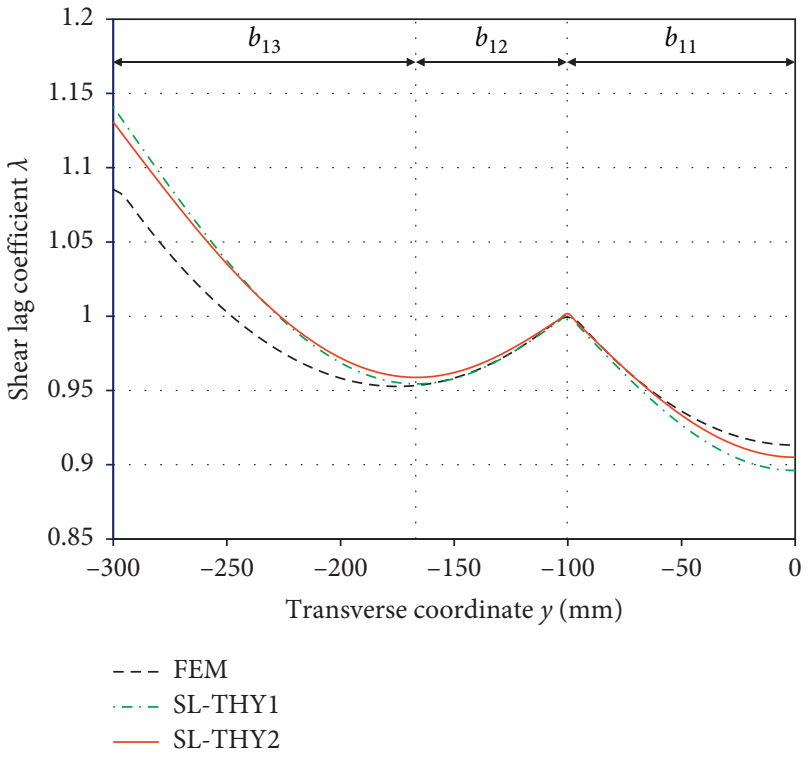

(b)

FIgURE 16: Continued. 


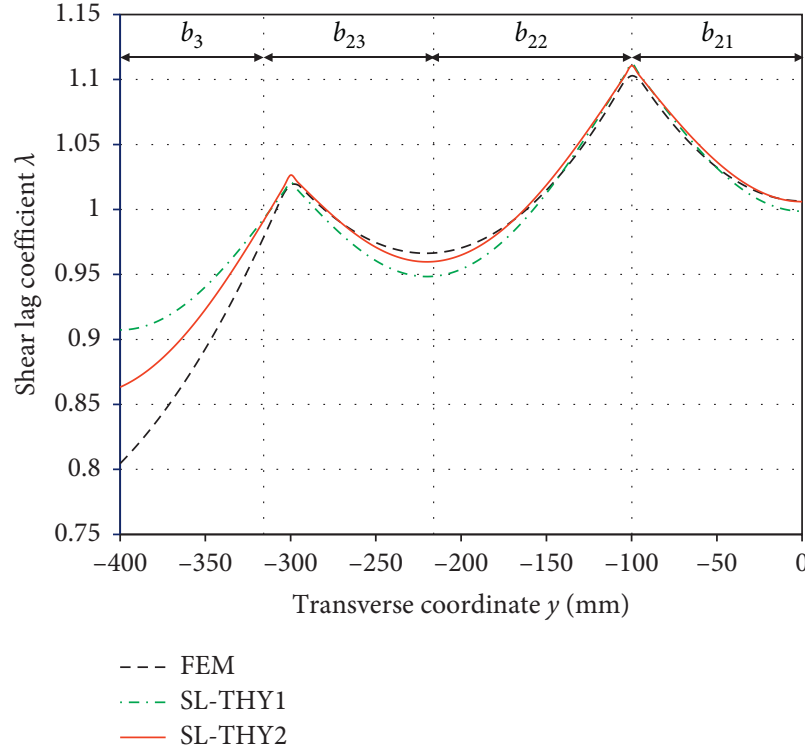

(c)

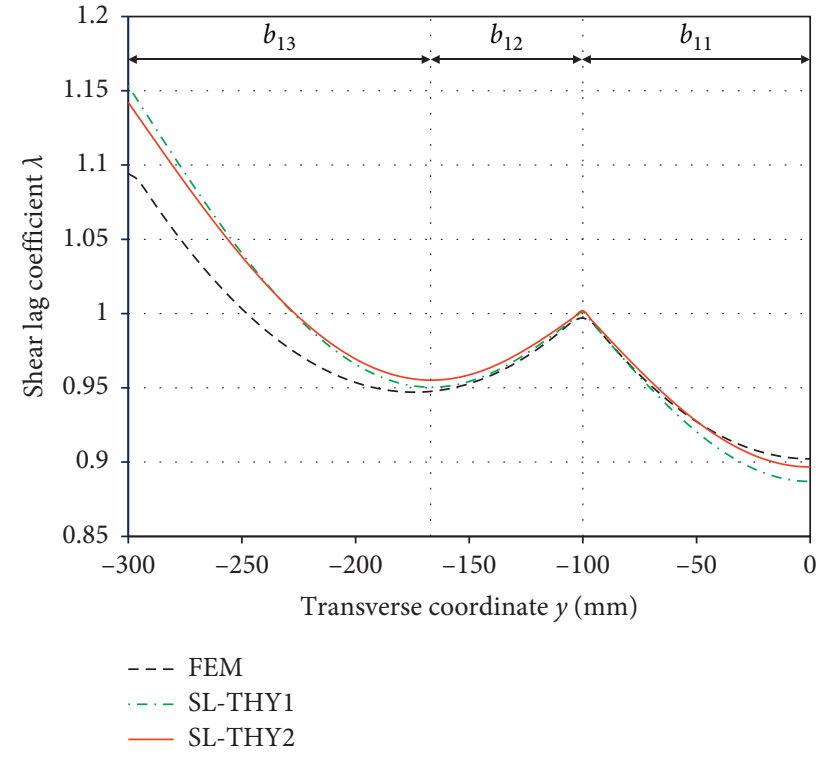

(d)

Figure 16: Shear lag coefficients of the fixed-end box girder. (a) Top flanges of midspan cross section $(x=900 \mathrm{~mm})$. (b) Bottom flanges of midspan cross section $(x=900 \mathrm{~mm})$. (c) Top flanges of 5/12-span cross section $(x=750 \mathrm{~mm})$. (d) Bottom flanges of 5/12-span cross section $(x=750 \mathrm{~mm})$.

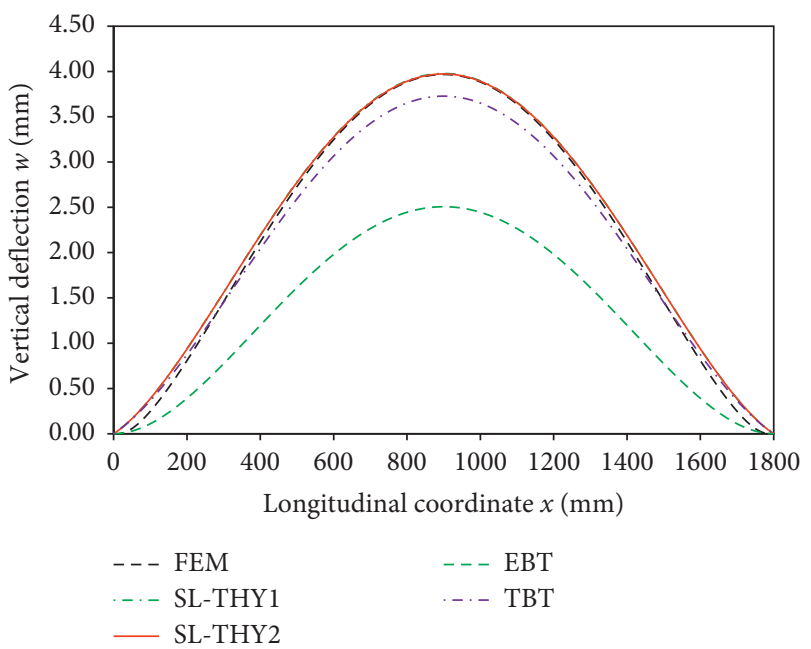

FIgURE 17: Comparison of vertical deflections predicted by the proposed methods (SL-THY1 and SL-THY2), EBT, TBT, and FEM analysis for the fixed-end box girder (example 4).

TABle 6: Vertical deflections of midspan and 5/12-span of the fixedend box girder (1B3C).

\begin{tabular}{lcccccc}
\hline & & FEM & EB & TB & $\begin{array}{c}\text { SL- } \\
\text { THY1 }\end{array}$ & $\begin{array}{c}\text { SL- } \\
\text { THY2 }\end{array}$ \\
\hline $\mathrm{L} / 2$ & $w(\mathrm{~mm})$ & 3.966 & 2.507 & 3.727 & 3.978 & 3.972 \\
$(900 \mathrm{~mm})$ & Error $(\%)$ & - & -36.78 & -6.03 & 0.30 & 0.15 \\
\hline $5 \mathrm{~L} / 12$ & $w(\mathrm{~mm})$ & 3.780 & 2.370 & 3.556 & 3.797 & 3.792 \\
$(750 \mathrm{~mm})$ & Error $(\%)$ & - & -37.31 & -5.94 & 0.45 & 0.31 \\
\hline
\end{tabular}

\section{Summary and Conclusions}

In this paper, an improved theoretical analysis method for predicting the shear lag effect in the thin-walled single-box multicell box girder is developed. The longitudinal warping displacement of each wall of the cross section is fully investigated and defined as the sum of the constant contribution from bending (TBT), the shear lag contribution, initial shear deformation contribution, and the internal force balance contribution. According to the bending shear flow distribution, the shear lag width $\left(b_{i j}\right)$ of flanges and the coefficients $\left(\alpha_{i j}\right)$ of shear lag warping functions are proposed. To satisfy the deformation compatibility conditions in flanges, the correction factors $\left(\xi_{k}\right)$ are introduced in building the warping displacement. In addition, the initial shear deformation $\left(\gamma_{03}\right)$ in the top lateral cantilever flange is innovatively introduced in the multicell box girder for shear lag analysis and the value of which is obtained by the designed procedure. With the given conditions, the transverse distribution function of shear lag warping displacement is deduced and proved to be expressed in the form of the cosine function.

Based on the principle of minimum potential energy, the two generalized displacements, normalized shear lag warping function and vertical displacement, can be derived by solving the governing differential equations with the associated load and boundary conditions. The solid FEM analysis is proved to be feasible through the sensitivity analysis of mesh size, and the proposed methods (SL-THY1 and SL-THY2) are validated with the solid FEM analyses conducted on four different multicell (two- and three-cell) box girders. The comparisons indicate that the proposed 
method can accurately predict the shear lag effect in the thinwalled single-box multicell box girder, and a considerable improvement can be achieved in the prediction accuracy when using SL-THY2 analysis.

It should also be noted that the proposed method is only valid in this context of the stated assumptions.

\section{Data Availability}

All data included in this study are available upon request by contact with the corresponding author.

\section{Conflicts of Interest}

The authors declare that they have no conflicts of interest.

\section{Acknowledgments}

Funds by the National Natural Science Foundation of China (Grant no. 51878151) and the China Scholarship Council (no. 201606090145) to provide financial support for the first author to visit the University of Houston are gratefully acknowledged. The authors would like to show their great appreciation to Dr. Xiangyong Ni for his kind suggestions.

\section{References}

[1] E. Reissner, "Analysis of shear lag in box beams by the principle of minimum potential energy," Quarterly of Applied Mathematics, vol. 4, no. 3, pp. 268-278, 1946.

[2] L. Dezi and L. Mentrasti, "Nonuniform bending-stress distribution (shear lag)," Journal of Structural Engineering, vol. 111, no. 12, pp. 2675-2690, 1985.

[3] X. Li, S. Wan, Y. L. Mo, K. Shen, T. Zhou, and Y. Nian, “An improved method for analyzing shear lag in thin-walled boxsection beam with arbitrary width of cantilever flange," ThinWalled Structures, vol. 140, pp. 222-235, 2019.

[4] X. Y. Li, S. Wan, J. B. Chen et al., "Analysis on shear lag effect in thin-walled box girders based on modified warping displacement function," Journal of Southeast University (Natural Science Edition), vol. 48, pp. 851-856, 2018, in Chinese.

[5] X. Y. Li, W. Fan, S. Wan et al., "Deflection calculation analyses on thin-walled box girder based on the theory of timoshenko beam and the energy-variation Principle," Journal of South China University of Technology (Natural Science Edition), vol. 46, pp. 51-57, 2018, in Chinese.

[6] M. Vojnić-Purčar, A. Prokić, and M. Bešević, "A numerical model for laminated composite thin-walled members with openings considering shear lag effect," Engineering Structures, vol. 185, pp. 392-399, 2019.

[7] I. C. Dikaros and E. J. Sapountzakis, "Nonuniform shear warping effect in the analysis of composite beams by BEM," Engineering Structures, vol. 76, pp. 215-234, 2014.

[8] Q. Z. Luo, Y. M. Wu, Q. S. Li, J. Tang, and G. D. Liu, "A finite segment model for shear lag analysis," Engineering Structures, vol. 26, no. 14, pp. 2113-2124, 2004.

[9] Q. Z. Luo, Q. S. Li, and J. Tang, "Shear lag in box girder bridges," Journal of Bridge Engineering, vol. 7, no. 5, pp. 308-313, 2002.

[10] Q. Z. Luo, J. Tang, and Q. S. Li, "Finite segment method for shear lag analysis of cable-stayed bridges," Journal of Structural Engineering, vol. 128, no. 12, pp. 1617-1622, 2002.
[11] Q. Z. Luo, Y. M. Wu, J. Tang, and Q. S. Li, "Experimental studies on shear lag of box girders," Engineering Structures, vol. 24, no. 4, pp. 469-477, 2002.

[12] Y.-H. Zhang and L.-X. Lin, "Shear lag analysis of thin-walled box girders based on a new generalized displacement," Engineering Structures, vol. 61, pp. 73-83, 2014.

[13] Y. H. Zhang, L. Li, and L. X. Lin, "Beam-segment finite element analysis on shear lag effect of thin-walled box girder adopting additional deflection as generalized displacement," China Civil Engineering Journal, vol. 46, pp. 100-107, 2013, in Chinese.

[14] Y. H. Zhang, Y. R. Hu, L. X. Lin et al., "Analysis on shear lag effect of thin-walled box girders based on a modified warping displacement mode," China Civil Engineering Journal, vol. 48, pp. 44-50, 2015, in Chinese.

[15] Y. H. Zhang and L. X. Lin, "Initial parameter method for analyzing shear lag effect of thin-walled box girders," Engineering Mechanics, vol. 30, pp. 205-211, 2013, in Chinese.

[16] Z. Lin and J. Zhao, "Least-work solutions of flange normal stresses in thin-walled flexural members with high-order polynomial," Engineering Structures, vol. 33, no. 10, pp. 2754-2761, 2011.

[17] Z. Lin and J. Zhao, "Modeling inelastic shear lag in steel box beams," Engineering Structures, vol. 41, pp. 90-97, 2012.

[18] X. Y. Ni, S. Y. Cao, and C. Q. Liu, "Shear lag and effective flange width of T-shaped short-leg shear walls," Journal of Engineering Research, vol. 6, pp. 31-52, 2018.

[19] X. Y. Ni and S. Y. Cao, "Shear lag analysis of I-shaped structural members," Structural Design of Tall and Special Buildings, vol. 27, no. 10, pp. 1-17, 2018.

[20] Y. Q. Qian and Y. Z. Ni, "Analysis of shear lag effect in singlecell box girder," China Journal of Highway and Transport, vol. 2, pp. 28-38, 1989, in Chinese.

[21] W. Yaping, Z. Yuanlin, L. Yuanming, and P. Weideng, "Analysis of shear lag and shear deformation effects in laminated composite box beams under bending loads," Composite Structures, vol. 55, no. 2, pp. 147-156, 2002.

[22] C. K. Lee and G. J. Wu, "Shear lag analysis by the adaptive finite element method," Thin-Walled Structures, vol. 38, no. 4, pp. 285-309, 2000.

[23] C. K. Lee and G. J. Wu, "Shear lag analysis by the adaptive finite element method," Thin-Walled Structures, vol. 38, no. 4, pp. 311-336, 2000.

[24] H. Nakai and C. H. Yoo, Analysis and Design of Curved Steel Bridges, McGraw-Hill Book, New York, NY, USA, 1988.

[25] M. H. Sadd, Elasticity: Theory, Applications, and Numerics, Butterworth Heinemann, Boston, MA, USA, 2005.

[26] ABAQUS, ABAQUS/Standard User's Manual, Version 6.9, Dassault Systèmes, Providence, RI, USA, 2009. 